ANUARIO DE Estudios MEDIEVALES

45/2, julio-diciembre de 2015, pp. 803-851

ISSN 0066-5061

doi:10.3989/aem.2015.45.2.07

\title{
LA GEOMETRIA DEL CÒDEX 80 (S. XII) DE LA CATEDRAL DE TORTOSA ${ }^{1}$
}

\author{
THE GEOMETRY IN CODEX 80 (XII) \\ OF THE CATHEDRAL OF TORTOSA
}

\author{
JOSEP LLUÍS I GINOVART \\ Universitat Rovira i Virgili \\ IGNASI J. BAIGES I JARDí \\ Universitat de Barcelona \\ JOSEP ALANYÀ I ROIG \\ Arxiu Capitular de Tortosa
}

Resum: La geometria del còdex 80 de l'Arxiu Capitular de Tortosa ha estat tradicionalment atribuïda, com un text únic, a Gerbert d'Orlhac (c. 940-1003). Una nova lectura del text ens permet assegurar que es tracta d'un text de caràcter miscel-lani de geometria, compost per tres textos independents: una part pertany a la Geometria Incerti Auctoris apòcrifa de Gerbert d'Orlhac; una altra, al fragment De Nuptiis Philologiae et Mercurii de Marcià Capella (fl. 430) Ergasticis Schematibus, del llibre VII de la Geometria; i, finalment, s'hi llegeix una glossa als Elementa d'Euclides (c. 325-c. 265 aC.) d'Al-Hajjāj ibn Yūsuf ibn Mațar (786833). La interpretació de les proposicions de la geometria dóna el coneixement de la mesura indirecta de llocs als quals no es pot accedir amb l'instrumental medieval, és a dir, amb astrolabi, miralls, bastons $\mathrm{i}$ escaires

Paraules clau: geometria medieval; geometria Gerbert; Gerbert d'Orlhac; Les noces de Filologia i Mercuri; Marcià Capella; elements Euclides; Al-Hajjāj.

\begin{abstract}
The geometry in codex 80 of the Capitular Archive has traditionally been understood as a complete text and attributed to Gerbert of Aurillac (c.940-1003). From a new reading of the text, we can say that it is a miscellaneous writing about geometry, composed of three independent parts: one containing the Geometria Incerti Auctoris apocryphical by Gerbert of Aurillac ( $c$. 940-1003); another one is a fragment of De Nuptiis Philologiae et Mercurii by Martianus Capella (fl. 430) from Ergasticis Schematibus of Book VII of the Geometry; and finally there is a gloss to the Elementa by Euclides (c. 325-c. 265 bC.) by Al-Hajjāj ibn Yūsuf ibn Mațar (786833). The interpretation of the geometrical propositions provides knowledge about the indirect measure of places which are inaccessible using medieval instrumental, the astrolabe, mirrors, cane and squares.
\end{abstract}

Keywords: medieval geometry; Geometria Incerti Auctoris; Gerbertus Aureliacensis; De Nuptiis Philologiae et Mercurii; Martianus Capella; Elementa Euclidis; AlHajjāj.

\footnotetext{
${ }^{1}$ Abreviatures utilitzades: ACTo = Arxiu Capitular Tortosa; $(\mathrm{Bub})=$ edicció de Bubnov 1899; $($ Pez $)=$ edicció de Pez 1853; $(\mathrm{Oll})$ = edició de Olleris 1876.
} 


\section{SUMARI}

1. Obres científiques a l'Arxiu Capitular de Tortosa.-2. La geometria del còdex ACTo 80.- 3. La Geometria Incerti Auctoris del còdex ACTo 80.- 4. Les proposicions de la Geometria Incerti Auctoris de 1'ACTo 80.- 5. De Ergasticis Schematibus de la geometria de Marcià Capella.- 6. La glossa d'Al-Hajjāj als Elementa d'Euclides.7. Conclusions.- 8. Bibliografia citada.

\section{OBRES CIENTÍFIQUES A L’ARXIU CAPITULAR DE TORTOSA}

El valor de les obres científiques dels segles XII-XIV de l'Arxiu Capitular de Tortosa ha estat ressaltat pels autors clàssics de la disciplina com J. M Millàs Vallicrosa, A. Cordoliani, J. Vernet, G. Beaujouan i, modernament, J. Martínez Gázquez, J. Gómez Pallarès i Ll. Cifuentes. L'International Catalogue of Mediaeval Scientific Manuscripts (2004) ${ }^{2}$ de l'Institut d'Història de la Ciència, de la Universitat de Munic, i de l'Institut Max Planck d'Història de la Ciència, de Berlín, esmenta una col·lecció de 22 còdexs, que recullen 68 obres de ciència.

El catàleg Jordanus dóna referència dels còdexs científics i n'especifica el seus números ${ }^{3}$. Al núm. 10, dedicat al còmput subdividit en 7 parts, hi destaca les següents parts: Martyrologium (ff. 1r-10r), Computus Graecorum et Latinorum (ff. 10r-37v), Benedictiones missarum (ff. 38r-40v), Ordinarium missarum (ff. 43r-214r). Destaca, també, els calendaris litúrgics del núm. 13 (ff. 13r-18v), les notes de còmput del núm. 51 (ff. 161v-162r) i el calendari del núm. 56 (ff. 1r-6v). Del còdex 80 fa relació a les obres següents: De viribus herbarum de Macer Floridus (ff. 99r-121r), Geographia, considerada anònima (ff. 122v-f. 145v), De Republica de Plató (ff. 146r-155r), Geometria de Gerbertus (ff. 159r-163r) i De astronomia de Gerbertus (ff. 163r-181v). Del còdex 88 fa referència a les Quaestiones de philosophia (ff. 1r-120v) i al Dictionarium super quatuor libros Sententiarum. Del núm. 115 cita les Quaestiones logicales d'Albertus de Saxonia (ff. 1r-25v), les Quaestiones super veterem artem de Johannes Buridanus (ff. 26r-74v), Circa Prim. Quaestiones d'Albertus de Saxonia (ff. 111r-196v). Es refereix, també, al Calendarium, Psalterium, Breviarium del manuscrit 111, als calendaris del 115 (ff. 1-9r) i del 119 (ff. 1r-330v) i els dels còdexs 120 i 140 (ff. 1r-335v i 1r-168v). Del núm. 144 en destaca les Constituciones del papa Alexandre III (ff. 1r-37r), la Philosophia (ff. 38r-90v) i el liber Cirurgie (ff. 90v-95r). Així mateix, destaca

\footnotetext{
${ }^{2}$ Catàleg Jordanus, accessible a: http://jordanus.badw.de [consulta: 01/06/2015].

${ }^{3}$ ACTo, núms. 10, 13, 34, 51, 56, 80, 88, 108, 111, 115, 119, 120, 140, 144, 174, 186, 200 , 226, 234, 239, 259 i 274 bis.
} 
el calendari del còdex 174, les obres de Gualterius de Burley, Tractatus de intentione et remissione formarum i De activitate (ff. 1r-34v), recollides al còdex 186, les Quaestiones super librum phisicorum d'Aegidius Romanus copiades al còdex 200 i l'obra del citat Gualterius de Burley, Super libros phisicorum, del còdex núm. 226. El còdex núm. 234 recull diverses obres de medicina, entre les quals destaca el Liber Antidotarius (ff. 1r-45v), l'Herbolarius (ff. 46r-92v), el Liber graduum (ff. 149r-164), el Liber antibalomenon (f. 164) o el Liber de granis et fructibus (ff. 265r.-191v). Acaba la relació tortosina amb les obres de còmput dels còdexs 239, 249 i 274 bis.

Entre tots ells, el núm. 80 és un dels que crida més l'atenció. Cal fer, però, una revisió a la catalogació de Bayerri ${ }^{4}$. D'acord amb el seu inventari, l'anomenada Geographia, considerada anònima (ff. $122 \mathrm{v}-145 \mathrm{v}$ ), és en realitat el Rerum Nature Liber, en la descripció del Caput XLV, Terrae positio de Beda el Venerable (673-735). Incipit: Terra fundata est super stabilitatem suam. Abyssus est ei sicut pallium... Explicit: ortus occasusque stationis ac reditus videantur ${ }^{5}$. Per altra part, la que Bayerri cataloga com la Republica de Plató (ff. 146r-155r), és en realitat la traducció del Timaeus translatus commentarioque instructus de Calcidi (fl. 350), el qual comença al f. 146r citant textualment Socrates in exortationibus suis virtutem laudans ${ }^{6}$. La que s'anomena Geometria de Gerbert d'Orlhac (ff. 159r-161r) és un miscel-lani de varis autors; el f. 162r, mutilat, amb la numeració de posició, és de l'entorn d'Hug de Sant Víctor (c.1096-1141) ${ }^{7}$ i l'anomenada De astronomia de Gerbert (ff. 163r-181v) ja va ser identificada com un fragment del Dragmation Philosophiae de Guillem de Conques (1080-1145) .

\section{LA GEOMETRIA DEL CÒDEX ACTO 80}

Una part del còdex 80 (ff. 159r-161v) tracta de diferents qüestions geomètriques i ha estat definida fins ara con un text únic. Els primers a catalogar-lo, Denifle i Chatelain, el defineixen com: Geometricales tractanti diversitates mensurarum appellationes quibus utimur sunt he: digitus, unica palmus (cum figuris). Gerbertus, Geometria, c. 14. Pergam., alt 210, lat.150

\footnotetext{
${ }^{4}$ Bayerri 1962,pp. 223-229.

${ }^{5}$ Beda 1850 , pp. 265-278.

${ }^{6}$ Moreschini 2003, pp. 4-5. Edició de Claudio Moreschini, basada en la Plato Latinus, ed. Klibansky, editada J.H. Waszink, editio altera, Londinnii el Leidae (1975). La fixació del text comença: "Isocrates in exhortationibus suis virtutem laudans". A la clàssica dels Fragmenta Philosophorum Graecorum. Volumen II. Mulliachus 1867, p. 147, es presenta igual que al còdex de l'ACTo.

${ }^{7}$ Lluís i Ginovart 2005, pp. 236-237.

${ }^{8}$ Ronca 1997, p. LXII, identifica 75. Tortosa. Biblioteca Capitular, 80i.
} 
mill., saec. XII ${ }^{9}$. O'Callaghan el defineix com Fragmentos de los clásicos y otros autores antiguos. Volumen en $4^{o}$, parte en pergamino que pertenece al siglo XII: Además un tratado de Geometría con figuras geométricas, y otro del eclipse de sol ${ }^{10}$. Rubió i Lluch i Rubió i Balaguer el consideren l'únic text manuscrit de la Geometria de Gerbert que es conserva en les biblioteques medievals catalanes ${ }^{11}$.

Bayerri el descriu com: IV Tratado de Geometría. Cuaderno en pergamino, ff. 159-162. Caja de Escritura 190x137 mm. Geometricales Tractanti diuersitates premostrandum est... quas tibi ...incitant ad legendum ${ }^{12}$. Per la seva part, Aurelio Querol Lor, dóna la següent referència: Geometria. (Anònim), 180x140mm (caixa de text) ff. 159r-161v. Segle XII. anguli...trigoni ubi duo rectiant erit aliquis minor minimo ${ }^{13}$.

Més recentment, J. Martínez Gázquez i J. Gómez Pallarés ${ }^{14}$, s'hi refereixen com, Inc: Geometricales tractanti diversitates praemostrandum est. Expl.: trigoni vero duo recti erit aliquis minor minimo, especificant que hi ha mencions a Pitàgores i que s'utilitza l'astrolabi, tot ratificant les atribucions de l'obra que van donar Denifle-Chatelain i Querol. L'inclouen dintre dels tractats de geometria medieval pròxims a l'agrimensura.

J. Lluis i Ginovart, a la seva tesi doctoral ${ }^{15}$, identifica l'obra en l'edició de Bubnov, i elabora un estudi de les proposicions gràfiques en l'explicació i significat d'alguns dels esquemes del còdex. A l'exposició Paissatges Sagrats (Sant Mateu, 2005), de la fundació La Luz de las imágenes, el mateix autor presentava el Códice 80, obert pels ff. 161v, 162r i 163r, per resaltar el coneixement científic de les artes del quadrivium a la catedral de Tortosa ${ }^{16}$.

L'atribució del text del còdex també va presentar diferències segons els autors. Mentre els autors clàssics com Denifle i Chatelain o els Rubió l'atribueixen sense cap dubte a Gerbert, altres com Bayerri no entren en la paternitat de l'obra, o com Aurelio Querol, qui tradueix el terme incerti per anònim, tot buscant els seus orígens a l'entorn de Gerbert, encara que planteja altres hipòtesis com les de Boeci, Hug de Sant Víctor o Abraham bar-Hiya en referència a la numeració de posició del f. 162r.

\footnotetext{
${ }^{9}$ Denifle, Chatelain 1896, p. 16.

${ }^{10}$ O'Callagahn 1897, p. 74 .

${ }^{11}$ Rubió, Rubió 1914,p. 746. Es desconeixien llavors els treballs de Millàs Vallicrosa sobre el còdex 225 de Ripoll.

${ }^{12}$ Bayerri 1962, p. 228

${ }^{13}$ Querol 1989, p. 232.

${ }^{14}$ Martínez, Gómez 1994, p. 416.

${ }^{15}$ Lluís i Ginovart 2002, pp. 233-254.

${ }^{16}$ Lluís i Ginovart 2005, pp. 236-237.
} 
El còdex conté una part de text i una col·leció de dibuixos que corresponen a les proposiciones geomètriques, fets amb tinta sobre pergamí. L'escriptura cal datar-la clarament a la segona meitat del segle XII, per les formes més anguloses que presenta. La caixa d'escriptura és variable: 199x144 mm (f. 159); 191x134 mm, amb 43 línies i 2 figures al marge esquerre (f. 159r); 178x140 mm, amb 44 línies i 4 figures al marge esquerre (f. 159v); 203x144 mm i 189x138 mm, 42 línies i 6 representacions gràfiques al marge esquerre (f. 160r); 178x 140 mm, amb 46 línies de text i 3 figures (una pràcticament esborrada) al marge esquerre (f. 160v); 202x144 mm i 189x135 mm, amb 13 línies y 1 construcció gràfica al peu del text (f. 161r). Aquesta va acompanyada d'altres sis construccions elaborades per una altra mà, de la mateixa manera que el f. $161 \mathrm{v}$, amb deu construccions, en una caixa de 190x134 mm.

Després de la nova lectura podem afirmar que la Geometria és un text miscel-lani de geometria, compost per tres textos independents:

Una part de la Geometria Incerti Auctoris apòcrifa de Gerbert d'Orlhac (ff. 159r-160v.27), dels llibres III i IV.

Un fragment de l'obra De Nuptiis Philologiae et Mercurii de Marcià Capella (fl. 430) que pertany al De Ergasticis Schematibus del Llibre VII de la Geometria (f. 160v.28-f. 161r.5).

Una glossa als Elementa d'Euclides d'Al-Hajjāj ibn Yūsuf ibn Mațar (f. 161r.6-f. 161r.13).

\section{LA GEOMETRIA INCERTI AUCTORIS DEL CÒDEX ACTO 80}

La geometria del còdex de Tortosa (ff. 159r-160v.27), reconeguda com a Geometria incerti auctoris, va ser elaborada en l'entorn de Gerbert d'Orlhac, més tard papa Silvestre II (999-1003), i considerada en termes generals aquesta part d'apòcrifa ${ }^{17}$.

La referència al còdex tortosí no apareix en les principals edicions de l'obra de Gerbert: a la Patrologia de Migne (1853) (PL, CXXXIX), de Bernhard Pez (1683-1735), l'anomenada Geometria Gerberti formaria part del Caput XIV fins al Caput XXXII ${ }^{18}$. La segona de les edicions de la geometria pertany a Alexandre Olleris, on el text de Tortosa forma part dels capítols XIV

\footnotetext{
${ }^{17}$ El terme Incerti el proposà Nicolaus Mikhailovich Bubnov en la seva edició de 1888 . Altres prefereixen el terme "apocrip", és el cas de Tannery 1897, pp. 214-221, i del mateix Tannery, Clerval 1901, pp 487-543, així com a Beaujouan 1985, pp. 654-655.

${ }^{18}$ Pez 1853, pp. 115-127.
} 
fins al XXXII ${ }^{19}$. Finalment l'obra matemàtica de Silvestre II va ser editada per Nicolaus Mikhailovich Bubnov (edició russa de 1888 i llatina de 1899), la part del còdex de Tortosa pertany al començament del Liber IV i la major part al Liber III (Gia App. IV, I) ${ }^{20}$.

Als ff. 159r-161r apareixen unes figures geomètriques que posteriorment seran novament reinterpretades per un altra mà en els gràfics dels ff. 161r y 161v. Aquestes figures es poden comparar amb les de les edicions de Pez (Pez), Olleris (Oll) i Bubnov (Bub).

El text consta de 20 proposicions, amb quinze figures; s'utilitza la notació $P(a)$, per al text primitiu del còdex, que acompanya les figures del marge esquerre; aquestes han estat traçades amb instruments auxiliars (ff. 159r-161r). Les figures no van acompanyades de cap notació, a diferència de les edicions de Pez, Olleris i Bubnov. Posteriorment un altre autor interpretà el text i construí les figures del f. 161r-v, introduint la notació $P(b)$, per diferenciar-lo del primitiu. El segon autor interpreta el text amb altres setze figures, de les quals quinze són de la geometria de Gerbert. El nou autor introdueix numeració romana i lletres, amb referències abreviades i comentaris al text. La notació de la interpretació d'aquestes figures $P(b)$ és similar a la de les principals edicions de l'obra de Gerbert (Pez, Oll i Bub). El quadre comparatiu de les proposicions del còdex 80 de l'ACTo amb la de les principals edicions és:

\begin{tabular}{|c|c|c|c|c|c|c|}
\hline ACTo n $^{\mathbf{0}} 80$ & \multicolumn{2}{|c|}{ Edició Pez } & \multicolumn{2}{c|}{ Edició Olleris } & \multicolumn{2}{c|}{ Edició Bubnov } \\
\hline Proposició & Text & Gràfic & Text & Gràfic & Text & Gràfic \\
\hline P-1 & Cap.XIV & & Cap.XIV & & L.IV & \\
\hline P-2 & Cap.XV & & Cap.XV & & L.IV.1 & \\
\hline P-3 & Cap.XVI & & Cap.XVI & & L.III.1 & \\
\hline P-4 & Cap.XVII & F- XVII & Cap.XVII & F-38 & L.III.2 & F-43 \\
\hline P-5 & Cap.XVIII & F-XVIII & Cap.XVIII & F-39 & L.III.3 & F-44 \\
\hline P-6 & Cap.XIX & F-XIX & Cap.XIX & F-40 & L.III.4 & F-45 \\
\hline P-7 & Cap.XX & F-XX & Cap.XX & F-42 & L.III.5 & F-46 \\
\hline P-8 & Cap.XXI & & Cap.XXII & & L.III.6 & \\
\hline P-9 & Cap.XXII & & Cap.XXIII & & L.III.7 & \\
\hline P-10 & Cap.XXIII & F-XXIII & Cap.XXIV & F-43 & L.III.8 & F-47 \\
\hline P-11 & Cap.XXIV & F-XXIV-1 & Cap.XXV & F-44a & L.III.9 & F-48 \\
\hline
\end{tabular}

${ }^{19}$ Olleris 1867, pp. 427-441.

${ }^{20}$ Bubnov 1899, pp. 310-375; Gia III, I. (317-330) i Gia IV, I (336-338). 
LA GEOMETRIA DEL CÒDEX 80 (S. XII) DE LA CATEDRAL DE TORTOSA 809

\begin{tabular}{|c|c|c|c|c|c|c|}
\hline P-12 & Cap.XXIV & F-XXIV-2 & $\begin{array}{c}\text { Cap. } \\
\text { XXV(bis) }\end{array}$ & F-44b & L.III.10 & F-49 \\
\hline P-13 & Cap.XXV & F-XXV & Cap.XXVI & F-45 & L.III.11 & F-50 \\
\hline P-14 & Cap.XXVI & F-XXVI & Cap.XXVII & F-46 & L.III.12 & F-51 \\
\hline P-15 & Cap.XXVII & F-XXVII & $\begin{array}{c}\text { Cap.XX- } \\
\text { VIII }\end{array}$ & F-47 & L.III.13 & F-52 \\
\hline P-16 & Cap.XXVIII & F-XXVIII & Cap.XIX & F-48 & L.III.14 & F-53 \\
\hline P-17 & Cap.XXIX & F-XXIX & Cap.XXI & F-41 & L.III.15 & F-54 \\
\hline P-18 & Cap.XXX & F-XXX & Cap.XXX & F-49 & L.III.16 & F-55 \\
\hline P-19 & Cap.XXXI & F-XXXI & Cap.XXXI & F-50 & L.III.17 & F-56 \\
\hline P-20 & Cap.XXXII & F-XXXII & Cap.XXXII & F-52 & L.III.18 & F-57 \\
\hline
\end{tabular}

Taula 1. Correspondència del còdex ACTo 80 i les edicions de l'obra de Gerbert.

Algunes d'aquestes proposicions de la Geometria incerti auctoris de Gerbert han estat estudiades per Millàs Vallicrosa en el manuscrit 225 Rip. del Monestir de Ripoll ${ }^{21}$, en allò que toca a les operacions fetes amb astrolabi i en referència a la utilització de la reflexió dels miralls. Cal destacar també els estudis de Catherine Jacquemard ${ }^{22}$ i, en el context més general de l'astrolabi, d'Arianna Borrelli ${ }^{23}$. Marie-Thérèse Sarrade tornarà a fer-ho en un text de la geometria de Gerbert, en proposicions similars a les de Millàs, tot afegint la proposició de mesurar la profunditat d'un pou $^{24}$. L'obra relaciona els coneixements de geometria atribuïda a Gerbert amb el Quadern de Villard de Honnecourt (c. 1175c. 1240) del manuscrit de París (BNF, ms. fr. 190093), de caire arquitectònic. Altres interpretacions de les proposicions similars però en geometries posteriors són les de C. Jacquemard, O. Desbordes i A. Hairie ${ }^{25}$, Stephen K. Victor ${ }^{26}$ o Nan L. Hahn ${ }^{27}$. Finalment, R. Petti estudià geomètricament alguna de les proposicions de la pràctica de geometria de Leonardo Pisano $(c .1180-1250)^{28}$.

${ }^{21}$ Millàs 1931 pp. 155-168. Puigvert 2000,pp. 50-54.

22 Jacquemard 2000, pp. 81-119.

${ }^{23}$ Borelli 2008, pp. 129-188.

${ }^{24}$ Sarrade 1986, pp. 9-23. Fa la interpretació en base a la versió d'Olleris.

${ }^{25}$ Jacquemard 2007, pp. 79-124.

${ }^{26}$ Victor 1979, pp. 114-117, pp. 294-327. En especial en l'Artis cuiuslibet consummatio.

${ }^{27}$ Hahn 1982, pp. XLI-LXXV.

${ }^{28}$ Petti 2002, L'obra de Cristofano di Gherardo di Dino, a La pratica di geometria: Volgarizzata da Cristofano di Gherardo di Dino. A cura e con introd. di Gino Arrighi Domus Galilaeana (1966). 


\section{LES PROPOSICIONS DE LA GEOMETRIA INCERTI AUCTORIS DE L'ACTO 80}

Proposició 1. Practica quádam geometrica ad multa dimentien$d a$ (dimetienda). Pràctiques geomètriques destinades a mesurar moltes coses; Caput XIV. (Pez), Practicae quaedam geometriae ad multa dimentienda (Oll) i Liber IV (Bub) $)^{29}$.

f. 159r. Geometricales tractanti diversitates premo[n]strandum est quas ipsius artis tractatus spondeat utilitates, quatinus lectoris ingenium, insinuacionis.

Pràctiques geomètriques destinades a mesurar moltes coses. A qui hagi de tractar les diversitats geomètriques cal demostrar-li prèviament quines utilitats presenta el tractat del propi art per tal que la intel-ligència del lector... Puix aquest és una escrupolosa i abundosa descripció d'aquesta disciplina feta amb la indagació de tota mena de dimensions i amb la proporció justa d'indagacions... I, com ja s'ha dit, perquè sigui abastada amb més facilitat pels estudiosos, a cada teorema hi és adjuntada la seva figura.

PROPOSICIÓ 2. Nomina mesurarum quibus geometra utuntur (quibus). Noms de les mesures que empren els geòmetres. Cap. XV (Pez) i (Oll) i Liber IV.I (Bub) $)^{30}$.

f. 159r. Mensurarum appellaciones, quibus utimur, sunt he: digitus, uncia, palmus, sextans, que et dodrans appellatur, pes, [pondus, figura] laterculus, cubitus, gradus, passus.

El dit és la mesura més petita de les mesures agràries. La polzada, segons alguns, té tres dits; en opinió d'altres, que s'ajusta més a veritat, té un dit i un terç de dit. El pam té quatre dits i tres polzades. El sextant té dotze dits, nou polzades, tres pams. El peu té setze dits, dotze polzades, quatre pams, un sextant $i$ terç de sextant. El latercle té un peu en amplada, vint-i-tres polzades en longitud. El colze té un peu i mig, set pams, divuit polzades, vint-i-quatre dits. El grau té dos peus, la passa cinc, la perxa deu, el clima seixanta. L'acte, en amplada, té noranta (peus), en longitud, dos-cents quaranta. La jovada té 240 peus, en amplada, 120 en longitud. La centúria, 200 jovades. L'estadi té 625 peus, 125 passes. El mil·liari té mil passes, que són vuit estadis.

\footnotetext{
${ }^{29}$ Edicions, Pez 1853, pp.115-116; Olleris 1867, pp. 427-428; Bubnov 1899, p. 336. Es coneix com a proposició "Caput XIV. Quas utilitates ars geometrica spondeat?" de les edicions de (Pez) "Practicae quaedam geometriae ad multa dimentienda" (Oll) i Liber IV (Bub) "Geometricales tractanti diversitates praemostrandum est".

${ }^{30}$ Pez 1853, pp. 116-117; Olleris 1867, p. 428; Bubnov 1899, pp. 337-338.
} 
PROPOSICIÓ 3. Ad altitudinem cum astralabio meciendam. Per a mesurar l'altitud amb un astrolabi. Cap. XVI (Pez), Cap. XVI (Oll), Liber III.1 $(\mathrm{Bub})^{31}$.

f. 159r. Si fuerit altitudo in equalitate, tali poterit me[n]surari inspectione. Sumatur ab altimetra astralabium, et in medietate cuadrati in postica ejus planicię exarati constituatur mediclinium, [ut hac scilicet positione stet mediclinium] alterius partis astralabii in medietate $\mathrm{XC}$ graduum.

El procediment tracta de mesurar l'alçada on la part superior no té possibilitat d'accés. En situar-se al peu d'aquest, llavors es marxarà cap endavant i endarrera, de tal sort que quan l'instrument, entreguardant per l'alidada, marcarà exactament la diagonal del quadrat $\mathrm{o}$, el que és el mateix, els 45 graus. Llavors la distància que ha recorregut el que realitza la mesura serà igual a l'alçada de l'element, a la qual haurà d'afegir l'alçada del qui realitza la pràctica de la mesura. Ara bé, si el mediclini no es manté en la meitat del quadrat, sinó en el primer o en el segon o en el tercer o en algun altre grau del quadrat, dels 12 graus comparats, aquella relació que hi hagi entre aquells graus del quadrat i 12 , tal serà la mesura agregada entre la superfície i l'altitud a mesurar.

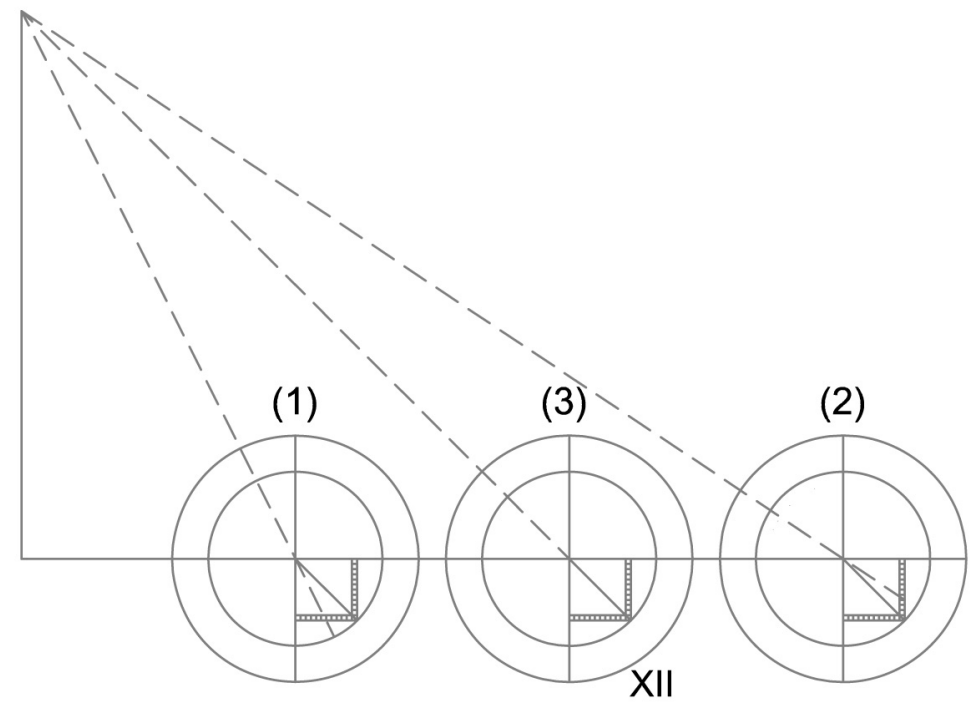

Fig. 1. Interpretació. Proposició 3 de Gerbert del còdex 80 ACTo.

${ }^{31}$ Pez 1853, pp. 117-118; Olleris 1867, p. 429; Bubnov 1899, pp. 317-318. 
Considera tan sols una relació entre la graduació, de l'I al XII del quadrat d'ombres $(g)$ i 12 , de la mateixa manera que la distància $(d)$ que ha de recórrer el mesurador i l'alçada $(a)$ que es volia mesurar: d/a= g/12 l'umbra versa del quadrat de les ombres, el costat vertical, encara que no especifica si és el costat d'orient o de ponent. Per ajustar la mesura als 12 graus del mediclini, aquest ha de passar per l'umbra versa, bé d'orient o occident, i l'umbra recta, la de la cara septentrional del quadrat de l'astrolabi. En general, les solucions de l'umbra versa son:

\begin{tabular}{|l|c|c|c|c|c|c|c|c|c|c|c|c|}
\hline \multicolumn{10}{|c|}{ Graus quadrat umbra versa } \\
\hline Graus & I & II & III & IV & V & VI & VII & VIII & IX & X & XI & XII \\
\hline Proporcionalitat & 12 & 6 & 4 & 3 & 2,4 & 2 & 1,71 & 1,5 & 1,33 & 1,2 & 1,09 & 1 \\
\hline Distància/Alçada & 12 & 6 & 4 & 3 & $2+2 / 5$ & 2 & $1+5 / 7$ & $1+1 / 2$ & $1+1 / 3$ & $1+1 / 5$ & $1+1 / 11$ & 1 \\
\hline
\end{tabular}

Proposició 4. Ad altitudinem inaccessibilem ob fluvii vel vallis impedicionem cum oroscopo mesciendam. Per mesurar amb l'oròscop una altitud inaccessible. Cap. XVII (Pez), Cap. XVII (Oll), al Liber III.2 (Bub) ${ }^{32}$.

f. 159r. Ad altitudinem inaccessibilem ob fluvii vel vallis impeditionem, si[t] altitudo quelibet, ut [est] a b, sitque fluvii vel vallis impedicio, ut est b c. Sume horoscopum stans in ripa c, et per utrumque foramen mediclinii summitatem a dilige[n]ter inspice.

Per mesurar una altitud inaccessible per causa de l'obstacle d'un riu o d'una vall, qualsevol que sigui l'altitud, com és $a b$, i tingue l'obstacle d'un riu o d'una vall, com és $b c$. Estant dret a la riba $c$, pren l'horòscop i per un $\mathrm{i}$ altre forat del mediclini mira amb atenció el punt més alt $a$. Examina atentament el nombre de graus que hi ha en la mesura o realitat del quadrat, que, per exemple, s'anota amb el nombre quaternari [IV], pel qual sigui dividida la summa de tot el quadrat, és a saber 144, i la quarta part obtinguda, que són 36, sigui escrita. Després d'això, sigui mesurada una certa quantitat d'espai de $c$ $a d$, [cap enrera] la qual, per exemple, sigui de 40 peus. Novament, estant dret en el límit $d$, pren l'horòscop i per un altre forat, com abans, mira el punt més alt $a$. Examina novament el nombre de graus existents en el quadrat, que ve signat amb el nombre ternari [III], pel qual novament sigui dividida la summa

${ }^{32}$ Pez 1853, p. 118; Olleris 1867, pp. 429-430; Bubnov 1899, pp. 318-319. Figures: (Pez. XVII) "A, altitudo, 3, 3, 18, 36, B, 120,D, B vallis vel flumen, C, 40 pedum, D"; a (Oll.38), “A,B,C,D, altitudo, XL, III, XLVIII, IV, XXXVI, CXX, XL, pedum”, a (Bub.43) "a, b,c,d, altitudo, XL, III, IV numerus graduum, XLVIII, numerus graduum III, XXXVI, CXX, XL, pedum amb mesura III, IV en gradus". 
de tot el quadrat, i la tercera part, que és 48 , juntament amb la quarta, que és 36 , sigui anotada, i el número menor, que és 36 , sigui restat del major, que és 48 , i el que en queda, que és 12 , [sigui comparat amb el costat del quadrat, que també és 12 , i el número remanent i el costat del quadrat siguin declarats iguals, i així com l'últim remanent 12 és declarat igual al costat del quadrat, que també és 12]. Així sigui afirmat que l'espai $d c$ és igual a l'espai $a b, \mathrm{i}$ essent l'alíquota [proporcional] un ternari, a l'últim número dels graus que són 12 [3/12], [cal declarar que la mateixa part, de l'espai $a b$, ha de ser a la totalitat de l'espai $d b$ ]. Així, doncs, $a b$ és 40, com $c d$ és 40 , i el tot $b d$ és 160 , i és $120 b c$.

Gràfic ACTo (P-4b) [.a., .b., .c., .d.] [altitudo mecienda.] [xxx.vi] [.ix.iiii.] [.xl.viii.] [.iii.] [vallis. ;. c.xx.; .xl.] [vallis fluminis; .c.], (Pez.XVII), (Oll.38) (Bub.43).
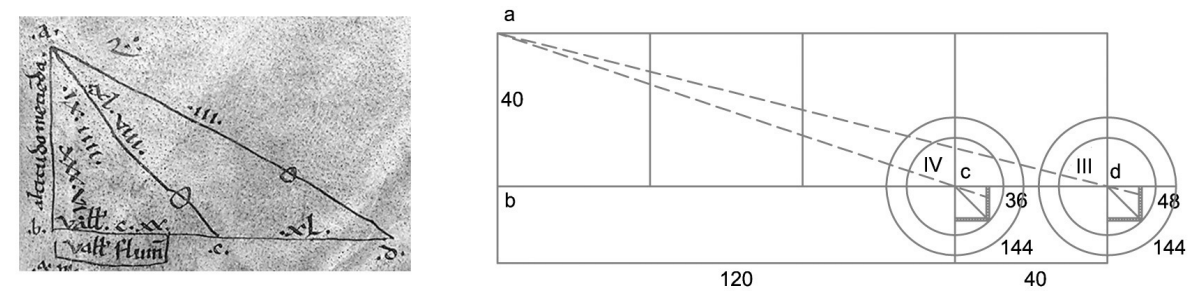

Fig. 2. Interpretació. Proposició 4 de Gerbert del còdex 80 ACTo. porcionals:

Es determinen així dues mesures tenint com a base dos triangles pro-

1. Al triangle $(a, b, c)$, existeix una proporcionalitat determinada pel quadrant de les ombres 144/36, o 12/4; bc/ab com 144/36, per tant $(b c)=$ $3(a b)$. L'alçada es tres vegades la distància de l'observador, en aquest punt $(c)$.

2. Al segon triangle $(a, b, d)$, on $a b / b d$ de la mateixa manera que $144 / 48,(b d)=4(a b)$

Des de la pràctica medieval amb el coneixement de la proposició anterior, el qui mesura sap que si l'astrolabi marca IV graus la distància recorreguda al punt $(c)$, és el triple de l'alçada que es vol determinar, i que, en III graus, al punt $(d)$, la distància recorreguda és 4 vegades l'alçada. Així es pot concloure que la distància que es recorre entre les mesures dels IV i III graus quadrats, és en realitat $4(a b)-3(a b)=(a b)$, que és l'alçada de l'element que es vol determinar. 
Un altra interpretació des del coneixement actual ${ }^{33}$ és que es pot calcular la distància $(a c)$, donat que si l'observador ha canviat de posició en 40 unitats i la mesura amb l'astrolabi, ha passat de tenir la proporció $1 / 4$ $(144 / 4=36)$ a la de $1 / 3(144 / 3=48)$, amb la qual cosa ha tingut un canvi de 12 unitats en el visor; així es pot plantejar la proporció: (40/12) com (bc/36), llavors el resultat de l'operació és 120 , que és la mesura de la distància que no era accessible per l'existència del curs fluvial. El valor de la altura queda perfectament determinat per la mesura directa amb l'astrolabi, al punt $(c)$ es determina una proporció entre (4-12) i $(b a-120)$, d'aquí que $(b a)=40$. També des de $(d)$ on (3-12) i $(b a-160)(b a)=40$.

De fet l'anàlisi des de la teoria de la proporcionalitat medieval dels números, tant des del punt de vista aritmètic, geomètric o de la teoria musical, l'estructura bàsica de la proposició parteix de la relació entre els números 4 i 3, diatessaron i la seva relació està en ordre sesquitercia. Sobre qualsevol patró de base, la diferència de unitats de mesura horitzontal que és directa, és la unitat que determina la posició vertical.

PROPOSICIÓ 5. Item de eodem cum horoscopo. Continguts segons les edicions: Cap. XVIII (Pez), Cap XVIII, Item de eodem (Oll) i del Liber III.3 $(\mathrm{Bub})^{34}$.

f. 159r. Si quod eminens inaccessibile fuerit estimandum cum oroscop[i]o, stet altimensor in meciendi [eminentis] artifinio, suspiciatque per utrumque foramen mediclinii, quo[u]sque intueatur altitudinis mensurande cacumen. Quo inspecto, gradus quadrati.

Si s'ha de mesurar amb l'horòscop una eminència inaccesible (cim), l'altímetra estigui dempeus en el límit que l'art assenyala per mesurar una eminència i prengui a les mans l'astrolabi i miri per un i altre forat del mediclini fins que vegi el cim de l'altitud a mesurar. Un cop vist el cim, siguin numerats els graus del quadrat, els quals, a manera d'exemple, siguin comptats en nombre de 3 , que en el costat del quadrat és contingut quatre vegades $\mathrm{i}$ dóna 12. Un cop fet això, cal continuar mirant al davant i al darrere [darrere] de l'astrolabi fins que hom vegi novament el cim ja vist de l'eminència a me-

\footnotetext{
${ }^{33}$ Sarrade 1986, p.13. Interpretació de la proposició amb el quadrant dividit en 144 parts, amb la diferència en graus $(48-36)=12$ i la distància 40 ; llavors $(b c)=40 \times 36 / 12=120$. Millàs 1931, p. 165. Planteja el mateix problema des de la proporcionalitat dels dos triangles. Figura núm. 13.

${ }^{34}$ Pez 1853, pp. 117-119; Olleris 1867, p. 430. Bubnov 1899, pp. 319-320. Figures; (Pez. XVIII), "Visus 2 gradus, visus, 3 gradus, altitudo, mensor, mensor, duplum, 12"; a (Oll.39) "altitudo, mensor, visus III gradus, visus II gradus, duplum XII"; a (Bub.44) "altitudo VI, statura mensoris, visus II gradus, visus III gradus, duplum, XII planicies dupla altitudini“.
} 
surar. Un cop vist el cim de l'eminència, cal fixar l'atenció en el nombre de graus del quadrat, prenent-ne per exemple 2 , que en el 12 , això és en el costat del quadrat, és cert que s'hi conté 6 vegades, i l'interval de les posicions de l'altímetra anotable sigui de 12 peus. Un cop fet tot això, el continent menor del ternari, que és el quaternari, sigui restat una vegada del continent major, que és el senari, i conservi's a la ment el binari, que n'és el remanent, i l'interval de les posicions de l'altímetra haurà d'afirmar-se que és el doble de l'altura inaccessible. I per tal que això que diem sigui conegut en tots els casos cal posar una regla universal absolutament certa. Un cop feta la substracció de les quantitats o nombres continguts, si en queda un, l'interval de les posicions de l'altímetra serà igual a l'altura; si en queden dos, el doble; si tres, el triple, i així successivament. [Amb aital dibuix hom en fa la mostra perfecta].

$\mathrm{Al}$ gràfic (P-5b) [astrolabium .sus. , .iii. gradus] [astrolabium. ii.gradus] [altitudo.; mensor.; mensor.][planicies dupla.; altitudini.] [statura mensoris iuncta .xii. altitudini]. A les edicions (Pez.XVIII), (Oll.39) (Bub.44). El gràfic de la proposició aplicada a 3 i 2 i dos graus, donarà com a resultat que la distància recorreguda es doble (planitie dupla) que l'altura a mesurar (altitudo), de tal manera que ha operat gradus III; $(12 / 3=4)$, gradus II; $(12 / 2=6)$, així (6-4=2) per tant la distància recorreguda és el doble de la altura. i apliquen a la proposició tres del tractat gradus IV; $(12 / 4=3)$, gradus III; (12/3=4), així $(4-3=1)$ per tant la distància recorreguda és la de la altura ${ }^{35}$.
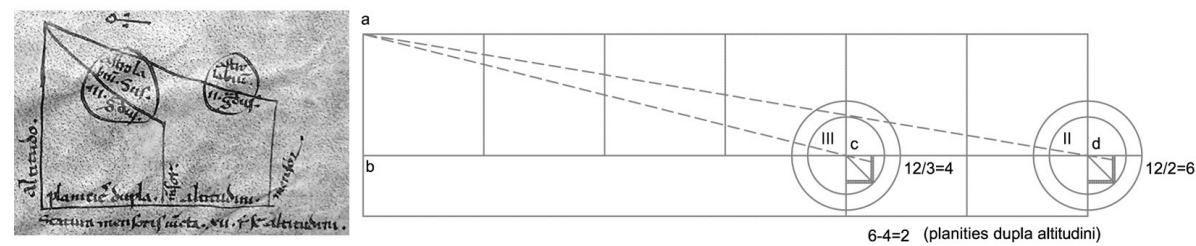

Fig. 3. Interpretació. Proposició 5 de Gerbert del còdex 80 ACTo.

\footnotetext{
${ }^{35}$ La construcció d'una proposició molt similar amb la del quadrant al còdex 225 de Ripoll 8 (ff. 20r-21r); "Cuiuslibet quantitatis de ligno aut de eramine construe quadratum in modum ABCD cuius quantitas quanto maior est tanto est melior". Millàs 1931, pp. 302-303. L'existència també documentada en la Practica geometriae (1223) de Leonardo Pisano (c.1180-1250), i en la Practica della geometria (1443) de Cristofano di Gherardo di Dino (c.1408-c.1446). La Practica geometriae (1223), Incipit septima distinctio de inuentione altitudinum rerum elevatarum et profunditatum atque longitudinum planierum, editada per Boncompagni 1862, pp. 202-206; Petti 2002, la (P-5), comença, "Se la larghessa overo lunghessa d'alcuno piano vuo; sapere, ordina uno quadrato di legnio overo di rame sì come tu vedi lo a.b.c.d. da ognj canto quadro et da ogni lato eghuale. Et tanto quanto è maggiore tanto è meglio; et or porrai in ciascuno anghulo una staggia d'una medesma lungbessa et stiano eghualmente ricte".
} 
Es determinen dos triangles rectangles:

1. Al primer, graus 3 , es planteja la proporcionalitat pel quadrant; $b c / a b$ com $12 / 3=4$, l'alçada és un quart de la distància de l'observador, en aquest lloc.

2 . El segon triangle, graus $2, b d / a b, 12 / 2=6,1$ 'alçada és un sexta part de la distància de l'observador en aquest lloc.

Dóna com a regla que en aquestes condiciones de practicar l'amidament de l'alçada, quan el visor de l'astrolabi és coincident en els III y II gradus, sobre l'element fix, la distància que va a recórrer el mensor és el doble que la mesura de l'alçada que no era accessible, donat que (6-4=2).

La mesura es practica amb dos números molt coneguts dintre de la teoria proporcional dels números 3/2 anomenada diapente que està en relació sesquilatera.

Aquesta proposició planteja una regla més general de practicar la mesura d'elements que no tenen un accés directe, ni tant sols a la seva base. La pràctica es determina mitjançant dos punts d'observació, sobre un element fix, i la relació d'aquesta en la distància en què canvia l'observador. D'aquesta manera es pot establir com una regla general que si s'observa un objecte, en un quadrant de dotze unitats:

1. Si l'observació realitzada, $4^{\circ}$ i $3^{\circ}$ respectivament, l'alçada és igual a la distància recorreguda. $(12 / 4 ; 12 / 3,4-3=1)$.

2. Si l'observació realitzada, $3^{\circ}$ i $2^{\circ}$ respectivament, l'alçada és la meitat de la distància recorreguda. $(12 / 3 ; 12 / 2,6-4=2)$.

3. Si l'observació realitzada, $2^{\circ}$ i $1^{\circ}$ respectivament, l'alçada és una sexta part de la distància recorreguda. $(12 / 2 ; 12 / 1,12-6=6)$.

4. Si l'observació realitzada, $4^{\circ}$ i $2^{\circ}$ respectivament, l'alçada és una tercera part de la distància recorreguda. $(12 / 4 ; 12 / 2,6-3=3)$.

5. Si l'observació realitzada, $3^{\circ}$ i $1^{\circ}$ respectivament, l'alçada és una octava part de la distància recorreguda. (12/3; 12/1, 12-4=8).

6. Si l'observació realitzada, $4^{\circ}$ i $1^{\circ}$ respectivament, l'alçada és una novena part de la distància recorreguda. (12/4; 12/1, 12-3=9).

\begin{tabular}{|l|c|c|c|c|c|c|c|c|c|c|c|c|}
\hline \multicolumn{10}{|c|}{ Graus quadrat umbra versa } \\
\hline $\begin{array}{l}\text { Distancia/ } \\
\text { Altada }\end{array}$ & $\mathbf{1}$ & $\mathbf{2}$ & $\mathbf{3}$ & $\mathbf{4}$ & $\mathbf{5}$ & $\mathbf{6}$ & $\mathbf{7}$ & $\mathbf{8}$ & $\mathbf{9}$ & $\mathbf{1 0}$ & $\mathbf{1 1}$ & $\mathbf{1 2}$ \\
\hline $\begin{array}{l}\text { graus quadrat } \\
\text { umbra versa }\end{array}$ & XII-VI & XII-IV & XII-III & VI-II & XII-II & II-I & & III-I & IV-I & VI-I & XI-I & \\
\hline $\begin{array}{l}\text { graus quadrat } \\
\text { umbra versa }\end{array}$ & VI-IV & VI-IV & IV-II & & & & & & & & & \\
\hline $\begin{array}{l}\text { graus quadrat } \\
\text { umbra versa }\end{array}$ & IV-III & III-II & & & & & & & & & & \\
\hline
\end{tabular}


Proposició 6. Ad altitudinem cum horoscopo meciendam. La proposició corresponent del Cap. XIX (Pez), Caput XIX (Oll) Liber III.4 (Bub) ${ }^{36}$.

f. 159r. Si vis cum horoscopo quamlibet metiri planiciem, dirige intuitum per utrumque foramen mediclinii, donec terminetur intuitus in meciende quantitatis limite.

Si vols mesurar qualsevol planúria amb l'horòscop, dirigeix la mirada per un i altre forat del mediclini fins que la mirada acabi fixant-se en el límit de la quantitat a mesurar. Després d'això, cal mirar en quin grau del quadrat està el mediclini i compari's el nombre de graus superior amb el 12, i aquella comparació que resulti dels graus respecte al 12 tal serà la comparació del mesurador respecte a tota la planúria. Per exemple: sigui l'estatura del mesurador $a b$, la planúria $b c$, el nombre de graus 3 , que, comparat amb 12 , resulta ser amb absoluta certesa la seva quarta part. Així, doncs, $a b$, que és l'estatura del mesurador, així $b c$, això és que resulta ser la quarta part de la planúria $[a, b]$, de la mateixa manera que el ternari és computat com la quarta part respecte al 12 .

Al gràfic (P-6b); [.a.; .b. ; .c.] [planiciei quarta pars] [astrolabi] [quarta pars planiciei] [.iii.] [planicies stature quadruprum meciende]. Gràfics (Pez. XIX), (Oll.40) i (Bub.45).
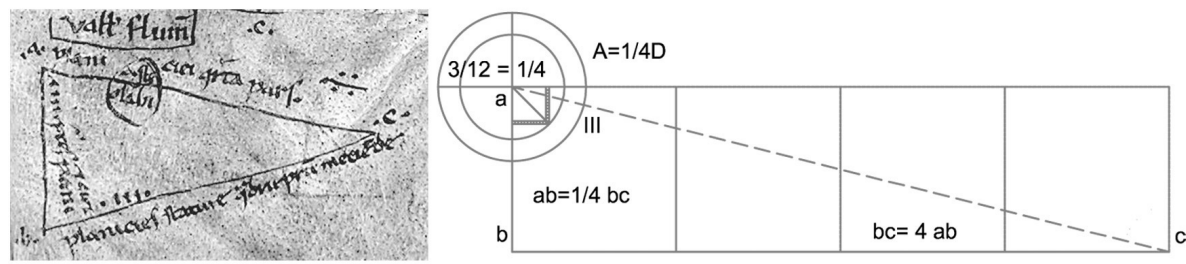

Fig. 4. Interpretació. Proposició 6 de Gerbert del còdex 80 ACTo.

La proposició tracta de mesurar Ad altitudinem cum horoscopo meciendam, parla d'altitudinem, encara que en realitat és una longitud la que es vol mesurar, en realitat es fará utilitzant el costat de l'umbra versa, el de ponent de l'astrolabi. Es mesura un element mitjançant la proporció establerta entre un triangle rectangle determinat per l'altura del mensor i el final de l'element,

\footnotetext{
${ }^{36}$ Pez 1853, pp. 119-120; Olleris 1867, p. 431; Bubnov 1899, p. 320. Figures: (Pez.XIX), "Visus, Statura mensoris, planities quadrupla mensor"; a (Oll.40) "a, b, c, statura mensoris, visus, planitius quadrupla mensor; a (Bub.45) astrolabium, a,b,c statura mensoris, visus, planitius quadrupla mensor".
} 
de manera que es pot determinar per un triangle conegut per un astrolabi o quadrant. Comença la pràctica en la utilitat de l'instrument en la directriu de la pinícula apuntat cap a terra en comptes de cap al cel. La mesura es determina a través del triangle $(a b c)$, de manera que $(a b)$, alçada del mensor fins l'alçada dels ulls, amb l'astrolabi apunta cap al final de l'esplanada $(c)$, representada per la hipotenusa $(a c)$, entreguardant així el límit de la distància que es vol esbrinar $(b c)$.

Es determina llavors:

1. La proporcionalitat pel quadrant; a tres graus com $3 / 12$, per tant 1/4. Es pot concloure que la mesura que es vol determinar en una visualització del quadrant a tres graus, la proporcionalitat entre els catets és de 1:4.

2. L'aplicació de l'instrument en què es realitza la mesura de forma bijectiva en la realitat, la distància ve expressada com quatre vegades la seva alçada de l'observador.

Coneixent així la mesura en funció de l'altura del mesurador, s'estableix una proporcionalitat, en funció de la mesura dels graus del quadrant, amb la visual de l'horitzó de l'element a mesura que representa la longitud total del que es vol mesurar. Així es poden determinar altres aplicacions:

1. La mesura del quadrant és 12 , l'alçada es igual a la distància.

2. La mesura de quadrant és 6,1 'alçada és la meitat de la distància, o la planitius dupla mensor.

3. La mesura del quadrant és 4, l'alçada és un terç de la distància, o la planitius tripla mensor.

4. La mesura del quadrant és 3, l'alçada és una quarta part de la distància, o la planitius quadrupla mensor, o com s'interpreta la proposició de Tortosa, l'alçada és quarta pars.

5. La mesura del quadrant és 2,1 'alçada és una sexta part de la distància, o la planitius sextupla mensor, o com s'interpreta la proposició de Tortosa, l'alçada és sexta pars.

6. La mesura del quadrant és 1 , l'alçada és una dotzena part de la distància.

Proposició 7. Ad meciendum horoscopo puteum. Té correspondència amb el Caput XX (Pez), Caput XX (Oll), Liber III.5 (Bub) ${ }^{37}$.

f. $159 v$. Primo perpendatur diligenter a geometra quatenus circulacio putei perpendiculo perpensa equalis habeatur. Deinde cujus

${ }^{37}$ Pez 1853, pp. 119-120; Olleris 1867, pp. 431-432; Bubnov 1899, pp. 320-321. Figures: (Pez.XX) D,4,C,8,E,B; a (Oll.41) d,c,e,b, (Oll .42) f, IV, IV, a,c, VIII, b,d,; (Bub.46); “d, statura geometra IV ped, c, ped IV, a, altitudo putei VIII, puteus, e,b". 
sit quantitatis ejus diametrum inquiratur. Invento diametro, stans mensor super putei labrum despiciat per mediclinium astralabii lateris oppositi terminum.

Abans de tot, el geòmetra ha de conèixer amb diligència que la circularitat [circumferència] del pou, apreciada amb la plomada, és igual. A continuació, s'ha d'esbrinar de quina quantitat és el seu diàmetre. Un cop trobat el diàmetre, estant dret damunt el voral del pou, el mesurador ha de mirar des de dalt el límit del costat oposat per mitjà del mediclini de l'astrolabi. Un cop vist el límit, el número de graus, en què el mediclini s'hagi mantingut en el quadrat, s'ha de comparar amb 12. I de la mateixa manera que el número de graus en el quadrat tindrà la relació amb 12 així també el diàmetre tindrà la relació amb la profunditat del pou i l'estatura del mesurador. Siguin, a títol d'exemple, 4 els graus i un diàmetre de 4 peus. Així, doncs, com el nombre quaternari [IV] és tres vegades en el 12, així és el diàmetre en la profunditat del pou i en l'estatura del mesurador. La qual estatura restada, allò que romandrà tinguesho per la profunditat del pou. Expressem la figura del pou caracteritzant-la amb unes lletres. Sigui, doncs, de 4 peus $a c$, això és el diàmetre; sigui l'altura del pou $a b$, el seu diàmetre $a c$, i l'estatura del geòmetra $c d$, de 4 peus. Vinga, constituïm de 4 peus $a c$, aquest és el diàmetre, i dirigim la mirada pel mediclini d' $a[\mathrm{~d}]$ a $b$. Després d'això, els graus, que, per exemple, són 4 amb els 12 , reunim-los en una triple proporció, i a $c$, que són precisament 4 , posem-los en la mateixa comparació respecte a $d e$. Així, doncs, $a c$ és de 4 peus, $d e$ és de 12 peus, a $c$ (millor $c d$ ), que és l'estatura del mesurador, és de 4 peus. Els quals 4 peus restats, això és $d c$ de $d e$, queden 8 peus $c e$, que és l'altura del pou.
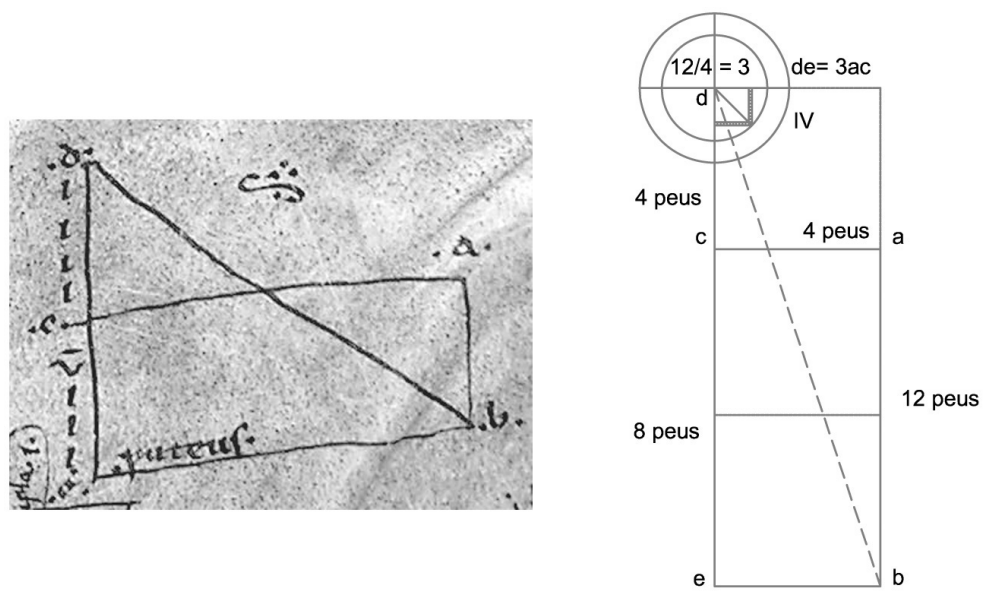

Fig. 5. Interpretació. Proposició 7 de Gerbert del còdex 80 ACTo. 
$\mathrm{Al}$ gràfic (P-7b), [.d.; .c.; .e.; .a.; .b.] [iiii; viii] [.puteus.]. Gràfics; (Pez.XX), (Oll41-42), (Bub46).

La proposició vol determinar la profunditat d'un pou, l'observador col-locat al peu del pou, amb l'ajuda de l'astrolabi, apuntant cap a terra, es determina la profunditat del pou ${ }^{38}$. La mesura es realitza sobre l'umbra recta, septentrió del quadrat, i com la mesura és d'una distància respecte a l'astrolabi, es conserva la proporcionalitat directa. En les anteriors proporcions la proporcionalitat també era directa, però es determinava una alçada respecte a l'astrolabi a través de l'umbra versa d'orient o occident.

El procés comença coneixent l'amplada del pou, que té 4 peus de diàmetre, desprès, ficat en peu, a quatre peus l'alçada sobre el brocall, apuntant al nivell de l'aigua amb l'astrolabi, que dóna en aquest cas de la proposició la mesura de (.IV. gradus). L'instrument determina un triangle rectangle de catets 4 i 12, que serà proporcional a l'amplada del pou, 4 peus, i l'alçada total, des de l'aigua fins a l'observador. Se sap, a més, que aquest té una alçada de 4 peus, que s'haurà de restar per saber la profunditat del pou.

Es determina:

1. La proporcionalitat pel quadrant; a quatre graus com 4/12.

2. El primer triangle $4 / 12$, en unitats de mesura de l'instrument, és proporcional a (4/de) en peus, on (de) és l'alçada total de la pràctica. Per tant s'estableix, per proporcionalitat; 4/12:4/(de) que la mesura total té 12 peus. Com es coneix l'alçada de l'observador, que són quatre peus, es determina que la profunditat del pou te vuit peus fins al nivell de l'aigua.

El criteri més general serà buscar mitjançant el quadrant de 12 unitats de referència en la marca gradus, s'estableix una relació coneguda; graus/12 que és proporcional a la boca/alçada del pou.

D'aquesta manera es pot determinar, coneixent l'amplada d'un pou, tot tenint en compte que finalment s'hi ha de descomptar l'alçada del qui realitza la mesura, que si:

1. La mesura del quadrant és 12 , l'alçada del pou a l'alçada del mesurador és igual a l'amplada.

2. La mesura de quadrant és 6, l'alçada a l'alçada del mesurador és el doble que l'amplada del pou.

3. La mesura del quadrant és 4, l'alçada del pou a l'alçada del mesurador és tres vegades la seva amplada.

4. La mesura del quadrant és 3, l'alçada del pou a l'alçada del mesurador és quatre vegades l'amplada del pou.

\footnotetext{
${ }^{38}$ Interpreta aquesta proposició, Sarrade 1986, p. 13. Estableix com a mesura de l'astrolabi la tercera divisió, per tant el resultat final $12 / 4 \mathrm{ED}=12$ peus i $\mathrm{CE}$ la profunditat de 8 peus. 
5. La mesura del quadrant és 2, l'alçada total del pou amb la del mesurador és sis vegades l'amplada.

6. La mesura del quadrant és 1 , l'alçada total, comptada la del del mesurador, és de dotze vegades l'amplada del pou.

Proposició 8. Cum quadrato astralabii in plano stantem per suam ipsius umbram quelibet altitudinem [ad] mensurandum. Per mesurar qualsevol altitud per la pròpia ombra d'un mateix, estant dret amb el quadrat de l'astrolabi en un pla. Editada: Caput XXI (Pez), Ad altitudinem arboris, columnae, vel turris per umbram cum astrolabio inveniendam del Caput XXII de (Oll), , descrita com a Liber III.6 (Bub) ${ }^{39}$.

f. 159 v. Cum quadrato astralabii in plano stantem per suam ipsius umbram quamlibet altitudinem ad mensurandam. Si vis alicujus arboris aut columpne vel turris, vel cujusquam talium in plano dumtaxat loco stantis, altitudinem per umbram ipsius invenire, suspenso astralabio, solis[que] radio per utraque foramina halchidade directim immisso.

Si vols trobar l'altura d'un arbre, d'una columna o d'una torre, o de qualssevol coses semblants a ells estant solament en un pla, un cop suspès l'astrolabi i deixant passar directament un raig de sol pels dos forats de l'alidada, mira en quina part del costat quadrat, que és dividit en 12 sectors, es manté directa la línia de la pròpia alidada, i qualsevol proporció que tingui el nombre de parts que apareixen sobre l'alidada respecte a 12, això és, la que tingui respecte a tot el costat del quadrat, no hi ha dubte que l'altitud tindrà la mateixa proporció, que vas voler trobar, respecte a l'ombra feta per l'objecte en qüestió en el pla. Per exemple: si apareixen a la part de dalt dues parts, respecte a les quals el 12 tingui una porporció séscupla, també serà séscupla l'ombra respecte a l'altitud; si n'apareixen tres, l'ombra serà quàdrupla; si 4, tripla; si 5, doble, partint en dos per dalt les quintes; si n'apareixen sis, serà doble; si són 7 , serà partint per dalt per cinc les setenes; si n'apareixen 8 , serà sesquiàltera; si 9 , sesquiterça; si 10, sesquicinquena; si 11, sesquionzena; i si es consideren alhora totes les parts, l'altitud de la cosa i de l'ombra serà igual. I absolutament, sigui de quina sigui la proporció el triangle que l'alidada faci en el quadrat, de la mateixa proporció serà el triangle que formarà l'ombra d'un cos estant plantat en una superfície plana. És a saber que en aquest triangle la base és l'ombra en la superfície plana; el catet és l'altura plantada; el raig del sol que limita transversalment l'ombra es veu que fa la funció de la hipotenusa.

\footnotetext{
${ }^{39}$ Pez 1853, pp. 120-121; Olleris 1867, p. 433; Bubnov 1899, pp. 321-322, al (LIII.6), sense figura. 
Utilitza per tant la relació de proporcionalitat entre el triangle rectangle, que es forma l'element a mesurar i la seva ombra, i l'altre triangle format per la aliada, halchidade, del quadrant, en la umbra versa. Utilitza per tant una variant de la proposició núm. 2 , amb el mateix criteri, la marca de l'alidada, el XII representarà el medietate numero graduum XLV.

$\mathrm{Al}$ començament del paràgraf de la definició, el copista de Tortosa diu: Verbi gratia: si due sint partes supra apparent, ad quas XII sexcuplam habeat superbiparciens quintas... En realitat el text fixat: $v . g$., si duae partes supra apparent, ad quas 12 sescuplam habeat proportionem, sescupla quoque ad altitudinem umbra; si tres appareant, quadrupla; si 4, tripla; si 5, duplex superbipartiens quintas (Pez), hauria de dir: Verbi gratia: si due sint partes supra apparent, ad quas XII sexcuplam habeat proportionem, sescupla quoque ad altitudimen unbra (Bub). Tal cosa pot portar a confusió, perquè s'ha omès [proporcionem, sescupla quoque ad altitudinem umbra; si tres appareant, quadrupla; si IIII, tripla; si V, duplex]. El que és el mateix quan la marca del quadrant són dos graus llavors l'obra és sis vegades l'alçada de l'element ${ }^{40}$.

Se suposa que el copista de Tortosa ha deixat la solució referida a les mesures de III, IV i V, perquè quan la definició superbiparciens quintas... del text, es tractaria en realitat de:

- si $V$, duplex superbiparciens quintas; $\mathrm{V}=2+2 / 5$, o $(12 / 5=2,4)$.

Faltarien llavors les definicions: si tres apparent; quadrupla; III=4, o $(12 / 3=4)$, si IV, tripla; IV=3, o $(12 / 4=3)$.

Dóna llavors les proporcions: si sex dupla; $\mathrm{VI}=2(12 / 6=2)$, si VII, superquinqueparciens septima; $\mathrm{VII}=1+5 / 7$; o $(12 / 7=1,71)$, si octo, sexqualtera; $\mathrm{VIII}=1+1 / 2 ;$ o $(12 / 8=1,5)$, si IX, sexquitercia; $\mathrm{IX}=1+1 / 3 ;$ o $(12 / 9=1,33)$, si $X$, sexquinquinta; $\mathrm{X}=1+1 / 5 ; \mathrm{o}(12 / 10=1,20)$, si undecim, sexquiundecima; $\mathrm{XI}=1+1 / 11$; o $(12 / 11=1,09)$, si omnes, equa erit altitudo et umbra; $\mathrm{XII}=1,(12 / 12=1)$.

En general les solucions serien:

\begin{tabular}{|l|c|c|c|c|c|c|c|c|c|c|c|c|}
\hline \multicolumn{110}{|c|}{ Graus quadrat umbra versa } \\
\hline Graus & I & II & III & IV & V & VI & VII & VIII & IX & X & XI & XII \\
\hline Proporcionalitat & 12 & 6 & 4 & 3 & 2,4 & 2 & 1,71 & 1,5 & 1,33 & 1,2 & 1,09 & 1 \\
\hline Graus/Ombra & 12 & 6 & 4 & 3 & $2+2 / 5$ & 2 & $1+5 / 7$ & $1+1 / 2$ & $1+1 / 3$ & $1+1 / 5$ & $1+1 / 11$ & 1 \\
\hline
\end{tabular}

\footnotetext{
${ }^{40}$ La proposició te com a base a Euclides (Opt. P-18), Euclides 2000, p.151. Proposició 18. Conèixer quina mida té una alçada quan fa sol. Sigui AB l'alçada donada i es necessari conèixer quina mida té. Sigui $\Delta$ l'ull i $\Gamma$ A el raig de sol es junta amb l'extrem de la magnitud AB i traci's fins l'ull $\Delta$. I sigui $\Delta \mathrm{B}$ l'ombra de $\mathrm{AB}$. I fiqui's una altra mesura $\mathrm{EZ}$ que, sense ser en absolut il-luminada pel raig, es junta amb ell a l'extrem $\mathrm{Z}$. Així, s'ha aplicat al triangle $\mathrm{AB} \Delta$ un altre triangle $\mathrm{EZ} \Delta$. Per tant $\Delta \mathrm{E}$ és a $\mathrm{ZE}$ com $\Delta \mathrm{B}$ a BA. I la raó de $\Delta \mathrm{E}$ a EZ és coneguda, donat que també la raó de $\Delta \mathrm{B}$ a $\mathrm{BA}$ és coneguda. $\mathrm{Y} \Delta \mathrm{B}$ és coneguda. Llavors també és conegut $\mathrm{AB}$.
} 


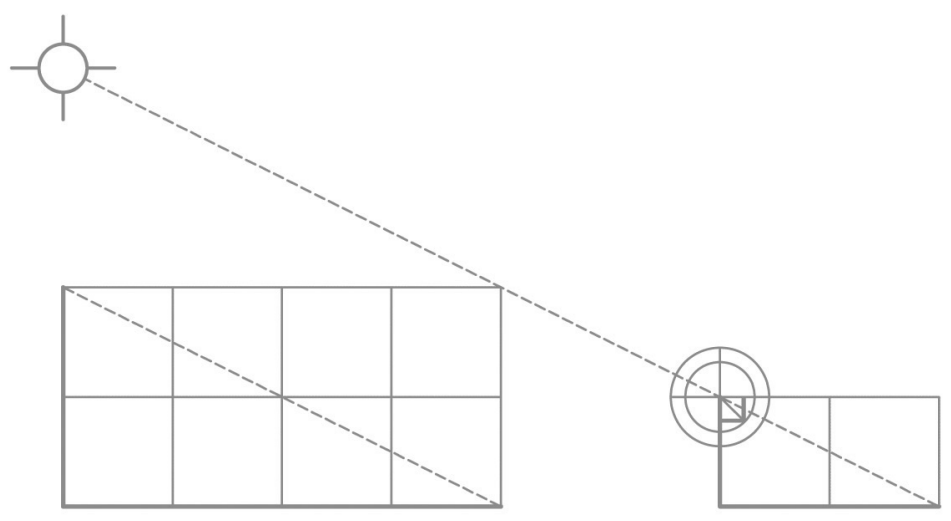

Fig. 6. Interpretació. Proposició 8 de Gerbert del còdex 80 ACTo.

PRoposició 9. Item de eadem re, que correspon a Caput XII (Pez), Caput XIII a (Oll) i al Liber III.7(Bub) ${ }^{41}$. El mateix sobre el mateix tema.

f. $159 v$. Si vis invenire, qualis conparacio sit alicujus umbre cum aliquo corpore in quacumque diei hora, sumatur astralabius, et, radio solis per mediclinii foramina exeunte, aspiciatur in quadrato in quo gradu mediclinium stet; et, qualis collacio.

Si vols trobar quina és la comparació d'una ombra amb qualsevol cos en qualsevol hora del dia, pren l'astrolabi i, mentre un raig del sol surt pels forats del mediclini, mira en el quadrat en quin grau està el mediclini; i qual sigui la correlació d'aquell grau respecte al 12, tal serà la correlació de l'ombra amb el cos, tenint en compte tan solament que, quan el mediclini estigui en el costat dret del clima, l'ombra és més gran que el cos; però quan el mediclini estigui en el costat esquerre, el cos serà més gran que l'ombra ${ }^{42}$.

El que reconeix la proposició és que fins que l'alçada del sol és menor de $45^{\circ}$, l'ombra és més llarga que l'objecte, mentre que en el moment que aquesta es major de $45^{\circ}$, l'ombra és menor que l'objecte.

Si els costats del quadrant estan dividits en 24 parts, del I-XII a la dreta, després es reconeix aquesta part del quadrant com umbra recta i del 12-24 a l'esquerra, (I-XII) graus quadrats situats com umbra versa, la relació entre l'ombra i l'element seran:

\footnotetext{
${ }^{41}$ Pez 1853, p. 121; Olleris 1867, pp. 433-434; Bubnov 1899, p. 322, sense figura.

${ }^{42}$ La proposició té com a base a Euclides (Opt. P-18); Euclides 2002, p. 151.
} 


\begin{tabular}{|c|c|c|c|c|c|}
\hline \multicolumn{2}{|c|}{ Dextro latere climatis (Umbra recta > 1) } & \multicolumn{3}{|c|}{ Sinistra latere climatis (Umbra versa <1) } \\
\hline Graus quadrant & Graus sol & Ombra/objecte & Graus quadrant & Graus sol & Ombra/objecte \\
\hline I & 3,75 & 12 & XI & 48,75 & $11 / 12$ \\
\hline II & 7,5 & 6 & X & 52.5 & $5 / 6$ \\
\hline III & 11,25 & 4 & IX & 56,25 & $3 / 4$ \\
\hline IV & 15 & 3 & VIII & 60 & $4 / 6$ \\
\hline V & 18,75 & $2+2 / 5$ & VII & 63,75 & $7 / 12$ \\
\hline VI & 22,5 & 2 & VI & 67,5 & $1 / 2$ \\
\hline VII & 26,25 & $1+5 / 7$ & V & 71,25 & $5 / 12$ \\
\hline VIII & 30 & $1+1 / 2$ & IV & 75 & $1 / 3$ \\
\hline IX & 33,75 & $1+1 / 3$ & III & 78,75 & $1 / 4$ \\
\hline X & 37,5 & $1+1 / 5$ & II & 82,5 & $1 / 6$ \\
\hline XI & 41,25 & $1+1 / 11$ & I & 86,25 & $1 / 12$ \\
\hline XII & 45 & 1 & 0 & 90 & - \\
\hline
\end{tabular}

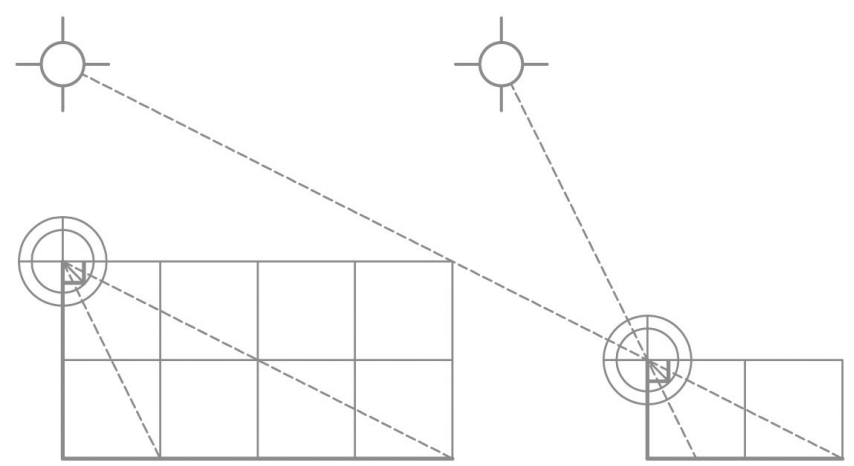

Fig. 7. Interpretació. Proposició 9 de Gerbert del còdex 80 ACTo.

Propocisió 10. Ad altitudienm cum speculo vel pelvi meciendam. La proposició del còdex té el seu corresponent al Caput XXIII (Pez), Caput XXIV a (Oll) i al Liber III.8 (Bub) ${ }^{43}$. Per a mesurar l'altitud amb un mirall o escudella ${ }^{44}$.

${ }^{43}$ Pez 1853,p. 121; Olleris 1867, p. 434; Bubnov 1899, p. 323. Figures; (Pez.XIII); "altitudo metienda, subdupla, splendor speculi, visus, statura mensoris subupla, dupla, speculum, dupla", (Oll.43); "altitudo metienda, splendor speculi, visus, statura mensoris, speculum", a (Bub.47); "altitudo metienda, resplendor speculi, visus, statura mensoris, speculum"

${ }^{44}$ Esmentat per Millàs 1931, p. 164, per al ms. 225 de Ripoll, figura núm.12, també a Sarrade 1986, p. 13. 
f. 159 v. Ad altitudienm cum speculo vel pelvi meciendam. Posito in speculo centro, vel in media scutella plena aque, constituatur in plano arvo et tandiu a geometra huc illucque [diligenter] trahatur, donec per medium centrum

Havent posat un centre en un mirall o al bell mig d'una escudella plena d'aigua, el geòmetra se situarà en una planúria i durant un cert temps portarà amb diligència i cura el mirall o l'escudella $a$ un lloc $i$ a un altre fins que al centre del mirall i al bell mig de l'escudella s'hi vegi la cima o punt més alt de la cosa a mesurar. Un cop trobat aquest punt més alt, mesuri's amb precisió aquell espai que existeix entre els peus del mesurador i el centre del mirall o el bell mig de l'escudella plena d'aigua, i després d'això, amb una precisió no menor, compari's a l'estatura del mesurador; i, quin sigui aquell espai de l'estatura del mesurador, tal serà la línia des del bell mig del centre del mirall fins a l'arrel de l'altitud de la cosa a mesurar. A tall d'exemple, s'hi posa aquí baix la figura plana:
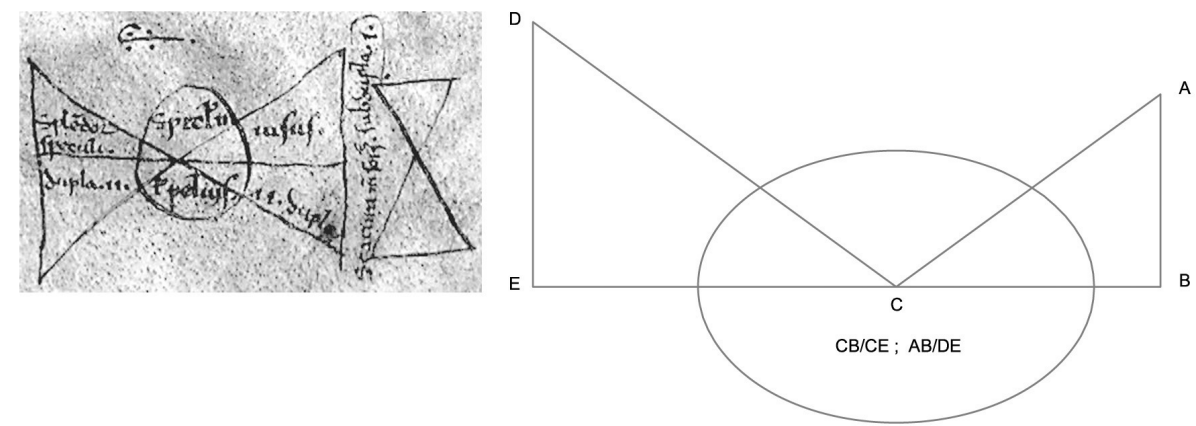

Fig. 8. Interpretació. Proposició 10 de Gerbert del còdex 80 ACTo.

$\mathrm{Al}$ gràfic $(\mathrm{P}-10 \mathrm{~b})$, [splendor speculi; speculum; visus] [dupla .ii.; vel pelvis .ii. dupla] [statura mensoris subdupla .i.]. Gràfics; (Pez.XXIII), (Oll.43), (Bub.47).

En la interpretació del dibuix: l'espill, speculum, o una tassa, pelvis, sobre la part superior el reflex de l'element que es vol mesurar splendor speculum, a l'altra part la visual, visus, sobre l'element de referència statura mensoris subdupla I. La distància al reflex figurat dupla II, II dupla. La interpretació gràfica en ser les distancies iguals; dupla II i II dupla, per tant les alçades dels elements statura mensoris subdupla I i la de l'element a mesurar han de ser iguals. La construcció gràfica és diferent a les editades per (Oll.43) i (Bub.47). La referència més directa és l'edició de Pez. 
Es resol el procés de la mesura situant un element que fa les funcions de mirall, l'observador es situa a una distància de l'element reflectiu fins que es visualitzi la part superior de l'element que es vol mesurar al centre d'aquest element reflectiu. Llavors la distància de l'element que es reflecteix fins al centre del mirall i la seva alçada és proporcional a la distància al geòmetra $\mathrm{i}$ la seva alçada.

La proposició és la mateixa que la d'Euclides (326-265 aC.) en l'òptica (P-19), Conèixer quina mesura té un alçada quan no $\mathrm{fa} \mathrm{sol}^{45}$. La teoria es basa en les bases del coneixement de la Catoptica del mateix Euclides, on: Als espills plans, convexes $i$ còncaus el raigs visuals es reflexen en angles iguals $(\mathrm{P}-1)^{46}$.

Proposició 11. Ad estimandam cujusque rei altitudinem sole lucente. Explicat com la proposició del Caput XXIV (Pez), Caput XXV a la de (Oll), i com a Liber III.9 (Bub) ${ }^{47}$. Per calcular l'altitud (altura) de qualsevol cosa a la llum del sol.

f. 159v. Ad estimandam cujusque rei altitudinem sole lucente quecumque res posita fuerit sub divo, umbram emittit, sed non sibi semper [co]equalem. Quapropter umbre.

Per calcular l'altitud de qualsevol cosa a la llum del sol. Qualsevol cosa que es posi sota la llum del dia emet una ombra, la qual, però, no és sempre igual a la cosa. Per això, vulguis elegir una part alíquota de la pròpia ombra. Després planta a terra un bastó, igual a aquesta part de l'ombra, i divideix l'ombra que cau en peus, pams o unces. Si l'ombra resultant fos major que el bastó, tota aquella quantitat en què l'ombra excedeix el bastó resta-la de cadascuna de les mesures que dóna el bastó. Ara bé, si l'ombra és menor,

\footnotetext{
${ }^{45}$ Euclides 2002, pp. 151-152. Proposició 19. Conèixer quina mida té una alçada quan no fa sol. Sigui $A B$ la latitud i sigui $\Gamma$ l'ull i sigui necessari conèixer quina mida té $A B$ sense que hi hagi sol. Col-loqui's un espill $\Delta \mathrm{Z}$ i perllongui's $\Delta \mathrm{B}$ en línia recta com $\mathrm{E} \Delta$ fins que coincideix amb l'extrem $B$ de la magnitud $A B$, i incideixi el raig $\Gamma H$ des de l'ull $\Gamma$ i es refracti fins que coincideixi amb l'extrem $\mathrm{A}$ de la magnitud $\mathrm{AB}$ i sigui $\mathrm{E} \Theta$ perllongació de $\Delta \mathrm{E}$ i tracés $\Gamma \Theta$ perpendicular a $\mathrm{E} \Theta$ des de $\Gamma$. Donat que el raig $\Delta \mathrm{H}$ ha incidit i HA es el corresponent raig refractat, les refraccions s'han produït en angles iguals, com diu als llibres de Catòptica. Per tant, l'angle corresponent a $\Gamma \mathrm{H} \Theta$ és igual a corresponent de $\mathrm{ABH}$. Però també el corresponent de $\mathrm{ABH}$ és igual al corresponent $\Gamma \Theta \mathrm{H}$; i per tant, el restant, el corresponent a $\Gamma \mathrm{H} \Theta$, és igual al restant, el corresponent a $\mathrm{HAB}$. Per tant, el triangle AHB és equiangle respecte al triangle $\Gamma \mathrm{H} \Theta$. Per tant, $\Gamma \Theta$ és a $\Theta H$ com $\mathrm{AB}$ a $\mathrm{BH}$. Per la raó de $\Gamma \Theta$ a $\mathrm{BH}$ és coneguda; llavors també la raó de $\mathrm{BA}$ a BH és coneguda; i HB es conegut. Per tant també AB és coneguda.

${ }^{46}$ Euclides 2002, pp. 212-213.

${ }^{47}$ Pez 1853, p. 121; Olleris 1867, pp. 434-435; Bubnov 1899, p. 323. Edicions de (Pez. XXIV), figura 1, "virga, umbra, figura 2 altitudo in umbra metienda,virga, umbra.; a les de (Oll.44), (Bub.48); figura 1 virga, umbra, figura 2 altitudo metienda, umbra".
} 
suma a les parts esmentades tota aquella quantitat en què el bastó excedeix l'ombra. I tot allò que en l'ombra creixi de l'augment o resti de la substracció, tingues-ho per mesura d'aquella cosa.

$\mathrm{Al}$ gràfic $(\mathrm{P}-11 \mathrm{~b})$, la figura es única virga, umbra, umbra, altitudo in umbra mecientis a diferència de les edicions (Pez.XXIV) de (Oll.44) i (Bub.48), on es descompon en dos triangles virga, umbra, i l'altre altitudo metienda, umbra.

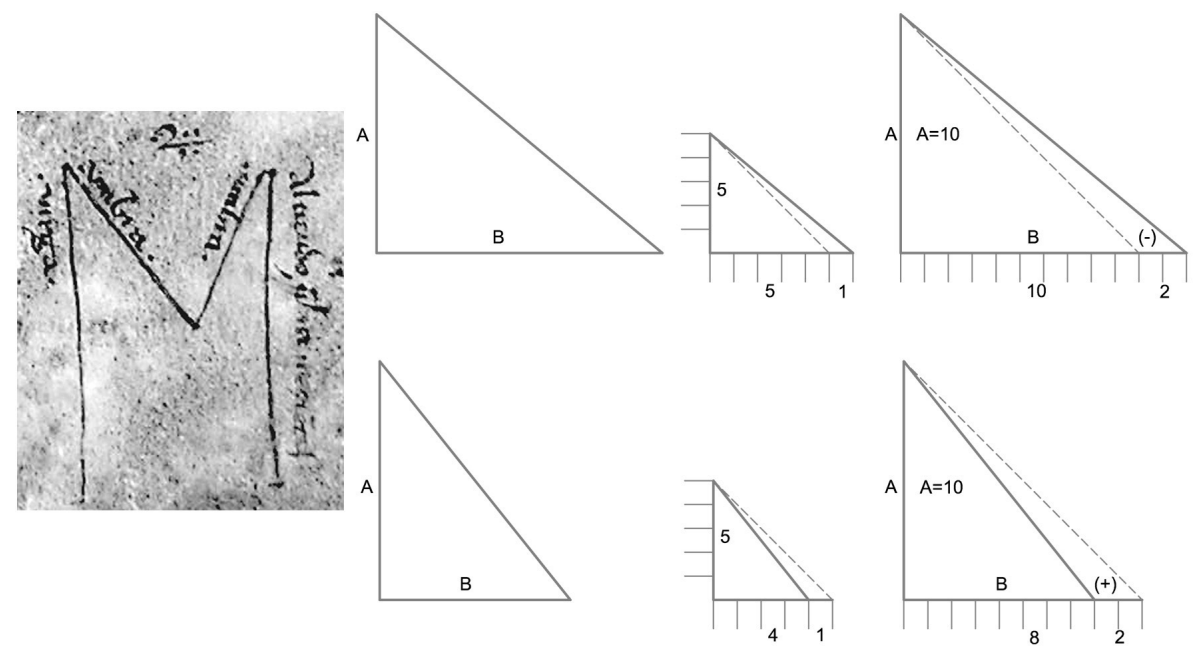

Fig. 9. Interpretació. Proposició 11 de Gerbert del còdex 80 ACTo.

Es realitza la pràctica utilitzant la proporció que existeix entre l'ombra del que es vol mesurar i la del gnomon (virgula) que es pren com unitat de mesura. Les ombres a subdividir en peus, pams o polzades dels dos elements són proporcionals. Llavors l'ombra del gnomon està en proporció a les seves mesures iguals que l'ombra de l'element que es vol determinar. La particularitat està en què aplica l'ombra a $45^{\circ}$, llavors l'alçada a mesurar és igual a l'ombra, d'aquí que: si l'ombra és major, se li resta la diferència fins arribar a patró el gnomon, això s'aplicarà proporcionalment a l'ombra d'aquest en relació a l'element a mesurar ${ }^{48}$.

${ }^{48}$ La proposició té com a base a Euclides (Opt. P-18), Euclides 2002, p. 151. 
PROPOSICIÓ 12. Ad altitudinem cum umbra ipsius et virgule umbra estimada, que correspon a la proposició del final de la Ad estimandam cujusque rei altitudinem sole luciente, Caput XXIV (Pez), i Caput XXV (bis) Ad altum cum arundine metiendam (Oll). Per tant, el còdex de l'Arxiu Capitular de Tortosa separa en dues aquesta proposició igual que a l'edició del Liber III.10 (Bub) ${ }^{49}$.

f. 159v. Ad altitudinem cum umbra ipsius et virgule umbra estimanda(m). Componitur etiam aliut instrumentum ad altitudinem sine dificultate inveniendam, quod hac de causa a sapiente, inventum putatur, quia visum humi adjungere difficile mensori.

Per calcular l'altitud d'un mateix amb l'ombra d'una vara. Hom compon també un altre instrument per trobar sense dificultat una altura, el qual hom creu que ha estat descobert per un savi per aquesta causa, és a saber perquè hom ha vist que és difícil atribuir-lo a un agrimensor i igualment inconvenient atribuir-lo a un seu espectador, i pren la quantitat de la seva magnitud de la magnitud de l'estatura del mesurador. Prenguem una canya d'una magnitud tal que en una doble proporció sigui proporcionada a la longitud del mesurador. Per la seva meitat li sigui unida ortogonalment una altra canya, la qual, igual a l'estatura del mesurador, tingui's per la meitat. Aquest instrument compost d'aquesta manera sigui traslladat pel mesurador a través d'un pla tot el temps necessari fins que per les puntes d'aquestes vares (canyes) sigui vista la part més alta de la cosa a mesurar. Un cop vista, tanta serà afirmada l'altura quant és mesurat l'espai existent des del lloc on és plantat el mesurador fins a la base de l'altitud, sumada l'estatura. Per exemple, sigui l'estatura del mesurador $a b$, la canya doblada $c d$, l'altra canya unida ortogonalment al mig de l'anterior $a e$, l'altura a mesurar $f g$, l'espai existent des del mesurador a la base de l'altitud $b g$. Ara bé, el mesurador no oblidi de cap manera això, és a saber que per a aquesta dimensió i per a tota cosa a plom cal penjar-hi el contrapés, que, format segons les regles de la Geometria, és preparat per a l'amidament. Per a exemple, s'hi posa aquí baix la figura plana.

\footnotetext{
${ }^{49}$ Pez 1853, p. 122; Olleris 1867, pp. 435-436; Bubnov 1899, pp. 323-324. Figures: (Pez. XXIV) figura 2; "F,C, visus, A,E, statura mensoris, altitudo metienda, statura ad junta, B,D,G, planities". A la de (Oll.44), figura 2; "f,c,a,e,b,d,g altitudo metienda", a la de (Bub.49), "f,c,a,e,b,d,g altitudo metienda".
} 

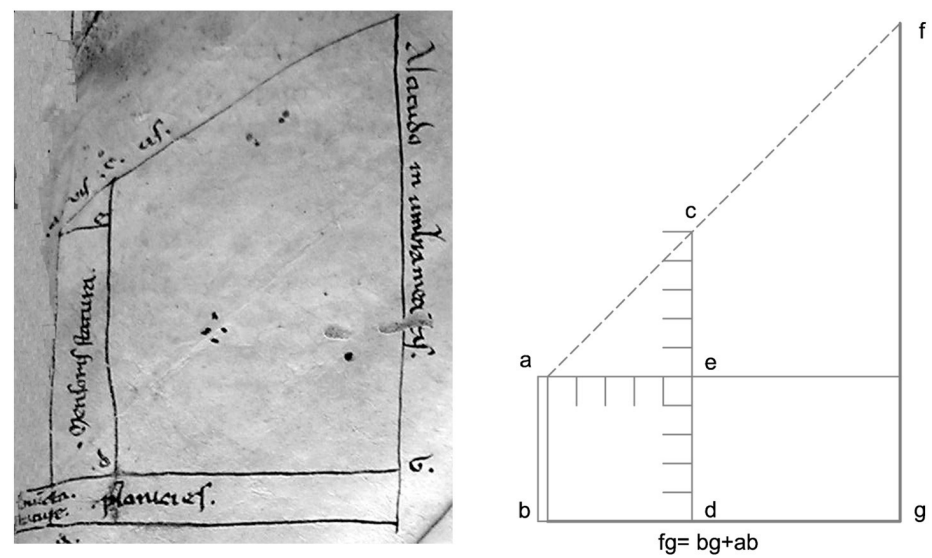

Fig. 10. Interpretació. Proposició 12 de Gerbert del còdex 80 ACTo.

A la interpretació (P-12b), [.a.; .c.; .e.; .d.; .f.; .g.] [.visus.] [.mensoris estatura; altitudo in umbra mecientis] [adiuncta stature .planicies.]. Gràfics de les edicions (Pez.XXIV) (fig. 2), (Oll.44) (fig. 2), (Bub.49).

Proposa la mesura d'una alçada en procediment que consisteix en la construcció d'un instrument auxiliar amb una canya, que serà un escaire $(a, e, c)$. Es construeix amb una canya (jaló) que té com d'altura $(c, d)$, de manera que la canya utilitzada té una alçada que és doble que l'alçada del geòmetra, al text mensor, d'altura $(a, b)$, situada a la meitat de l'alçada $(a, e)$. La construcció auxiliar estableix en realitat un escaire $(a, e, c)$, on els costats són iguals, isòscels, i por tant formen un angle de $45^{\circ}$, on es compleix que la distància és igual a l'alçada.

PROPORCIÓ 13. Ad planiciem virga vel arundine querendam, que és la que apareix en les editades; Caput XXV (Pez), Ad planitiem cum virga vel arundine metiendam del Caput XXVI a (Oll) i del Liber III.11(Bub) ${ }^{50}$.

f. 160. Ad planiciem [cum] virga vel arundine querendam. Stabiliatur harundo visui equiparata mecientis in terminio epiphanię, cui jungatur altera cujuslibet quantitatis ortogonali ratione; que scilicet sursum jusumque tandiu a planimetra ducatur, donec per utriusque harundinis summitates oppositus

${ }^{50}$ Pez 1853, p. 123; Olleris 1867, p. 436; Bubnov 1899, pp. 324-325. Gràfics: (Pez.XXV) "A, visus, B, virga pendens, E,C, planities metienda, D; a (Oll.45), figura 2; "a,b, virga pendens, e,c, planities metienda", a (Bub.50). figura 2; "a,b, virga pendens, e,c, planities metienda, arundo stans". 
Còdex (P-12b), [.a.; .b.; .c.; .e.; .d.] [.visus.] [pedes virga] [altitudo.] [planicies mecienda]. Gràfics: (Pez.XXV), (Oll.45), (Bub.50).
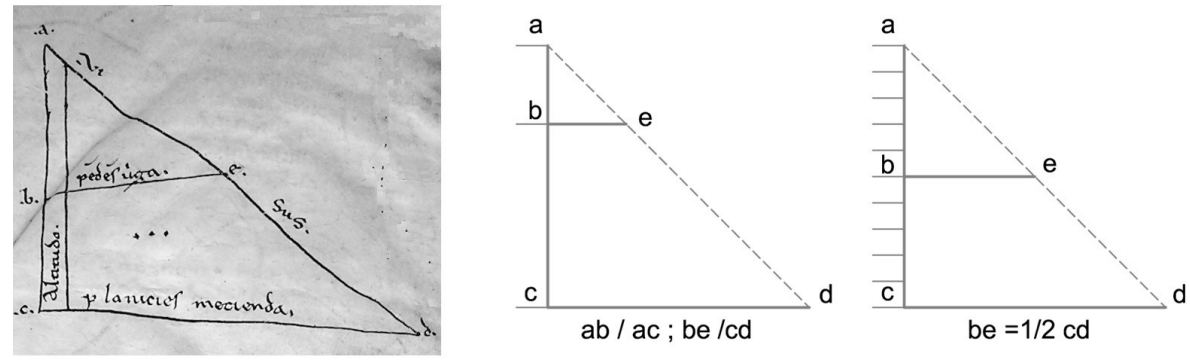

Fig. 11. Interpretació. Proposició 13 de Gerbert del còdex 80 ACTo.

Per mesurar una planúria amb un bastó o canya. Planti's una canya equiparada a la vista (visual) del mesurador en un punt fitat de tota la superfície visible, a la qual canya s'hi uneixi una altra de qualsevulla quantitat (o mida) en disposició ortogonal; la qual pugui el planímetra moure amunt $i$ avall tot el temps que calgui fins que sigui vist el límit oposat de la planúria pels punts més alts d'ambdues canyes. Un cop vist el límit, prengui's nota amb diligència (precisió) de la conjunció de les dues canyes i compari's la part superior de la canya fixa amb tota la seva pròpia quantitat des de la conjunció de l'altra i faci's la mateixa comparació de la vara pendent i del pla sense discussió, la qual més amunt s'ha dit feta des de la conjunció de la part superior amb la quantitat total de la canya fixa. I per tal que es torni més clar això que calculem amb l'expressió literal, afegim més avall un dibuix que farà evidents als ulls dels lectors els punts obscurs. Sigui la canya plantada equiparada a la visual del mesurador $a c$; sigui la planúria a mesurar $c d$; la vara pendent ortogonalment $b e$; sigui així mateix $a b$ la meitat de $a c$; i serà $b e$ la meitat de $c d$.

Es colloca l'observador front al element que es vol mesurar en situació horitzontal, en la visual de l'ull $(a)$ cap al punt final $(d)$. Després es situa a una alçada inferior a la vista un element horitzontal $(b, e)$, de mesura coneguda i es visualitza, l'ull (a) el final del bastó (e) i la longitud a mesurar $(d)$. Es construeix així un sistema proporcional; entre la part superior de la canya i l'ull $(a, b)$ i la canya $(b, e)$; i el qui mesura $(a, c)$ i la planura que es vol mesurar $(c, d)^{5 l}$.

${ }^{51}$ La proposició pot tenir com a referent l'Óptica d'Euclides. Euclides 2002, p.153. Proposició 21 . Conèixer quina mida té una longitud donada. Sigui $A B$ la longitud donada y sigui $\Gamma$ l'ull $i$ és necessari conèixer quina mida té la longitud $A B$. Incideixen els raigs $\Gamma A, \Gamma B$ i prengui prop 
PROPOSICIÓ 14. Ad altum meciendum cum harundine, que és l'editada: Caput XXXVI (Pez), la definida com a Figura ad altitudiem mensurandam del Caput XXVII (Oll), i la del Liber III.12 (Bub) $)^{52}$. Per mesurar una altura amb una canya.

f. 160. Ad altum meciendum cum harundine. Si quis superioris figure retro posite vim, qua mensuravimus planiciem, subtiliter inspexerit, istius quoque figure vis, qua altitudines metimur, eum prorsus latere non poterit. Parum enim hec distat a superiori figura, excepto quod superior in planicię, hec operatur in altitudine mensuranda. Sit altitudo mensuranda a b:
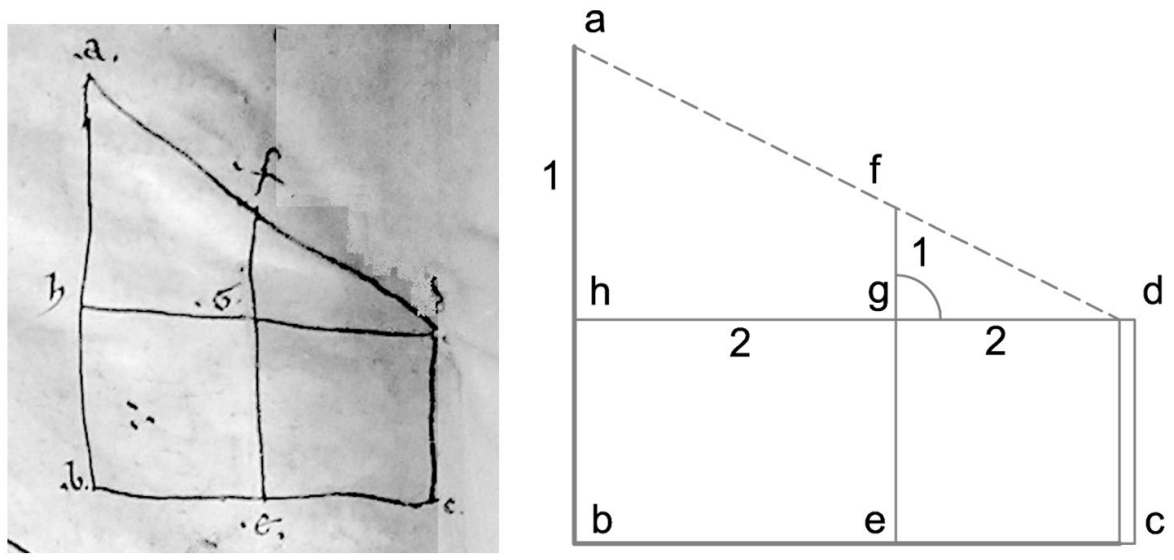

Fig. 12. Interpretació. Proposició 14 de Gerbert del còdex 80 ACTo.

A la figura (P-14b) es representa: l'alçada que es vol mesurar $(a, b)$; del qui mesura $(c, d)$; de l'element auxiliar $(f, e)$. Gràfics (Pez.XXVI), (Oll.46) i (Bub.51).

Per mesurar una altura amb una canya. Si algú inspecciona subtilment la naturalesa de la figura superior posada al darrere, amb la qual hem mesurat el pla, no se li podrà ocultar de cap manera la naturalesa d'aquesta mateixa figura, amb la qual mesurem altures. Puix aquesta es diferencia

de l'ull $\Gamma$ un punt a l'atzar $\Delta$ sobre el raig, i traci's des del punt $\Delta$ la recta $\Delta E$ paral'lela a $A B$. Donat que $\Delta \mathrm{E}$ s'ha traçat paral·lela a un dels costats, $\mathrm{BA}$, el triangle $\mathrm{AB} \Gamma$, llavors $\Gamma \Delta$ és a $\Delta \mathrm{E}$ com $\Gamma A \mathrm{~A} A \mathrm{AB}$. I la raó de $\Gamma \Delta \mathrm{a} \Delta \mathrm{E}$ és coneguda; llavors també la raó de $\mathrm{A} \Gamma \mathrm{AB}$ és coneguda. I $\mathrm{A} \Gamma$ és conegut. Per tant, també $\mathrm{AB}$ és conegut.

${ }^{52}$ Pez 1853, pp. 123-124; Olleris 1867, pp. 436-337; Bubnov 1899, pp. 325-326. Figures: (Pez.XXVI); A,F,H,g,D,B,E,C; a les de (Oll.46) i (Bub.51), a,f,h,g,d,b,e,c. 
poc de la figura superior, excepte que la figura superior opera sobre un pla a mesurar, i aquesta opera en una altura a mesurar. Sigui l'altura a mesurar $a b$; l'estatura del mesurador $c d$; la canya, amb què es mesuri l'altura, més llarga en estatura, $e f$; la línia portada ortogonalment des de la visual del mesurador per la canya fins a l'altura a mesurar $g h$. Un cop fet això, es compara $d g$ amb $g f$, i faci's la mateixa comparació de $d h$ amb $a h$, la qual es feia de $d g$ amb $g f$. Per exemple, la relació de $d g$ a $g f$ posi's doble i no menys; la relació de $d h$ a $h a$ sigui també certament doble. Si en la mesuració se sumen $b h$ i $h a$, quantitat que es considera igual a $d c$, que és l'estatura del mesurador, l'altura total $a b$ mesurada no admet dubte. Però com que pot esdevenir-se que $c b$ de vegades no sigui travessable, $h a$ no ens és conegut en absolut, encara que sigui proporcional, per la qual cosa el pla $b c$ haurà de ser mesurat pel darrere i caldrà compondre una altra figura semblant a la superior.

Geomètricament es determinen dos triangles proporcionals $(d, g, f)$ i $(d, h, a)$ on la seva relació donarà la solució a la pràctica de la mesura i dos rectangles $(h, d, b, c)$ i $(g, d, e, c)$ que es relaciona amb l'alçada del geòmetra. En termes de proporcionalitat s'estableix: al triangle $(d, g, f)$ de la canya que $(g, d)$ $:(g, f)$, (distància / alçada), de la mateixa manera que al $(d, h, a)$, on la distància $(h, d)$ o és a l'altura $(h, a)$, que es l'alçada des de la visual horitzontal, a la que haurà d'afegir $(d, c)$.

Proposició 15. De planitie mensuranda, que correspon a la proposició del Caput XXVII (Pez), la definida com a Figura ad metiendam altitudinem del Caput XXVII de (Oll) i a la del Liber III.13(Bub) ${ }^{53}$. Figura per mesurar una altitud.

$f$. 160. Meciatur planities $c i$, sitque statura mecientis $i k$; sit harundo equalis superiori $l m$; sit linea, ortogonaliter ducta a visu mecientis tendens ad altum per harundinem, $k n$. Post hec $k n, n l$ in quadrupla proporcione conferatur, et similiter [totum] $r h, h a$, quadruplum indubitanter dicatur:

${ }_{53}^{53}$ Pez 1853, p. 124; Olleris 1867, pp. 437-438; Bubnov 1899, p. 326. Els gràfics: (Pez. XXVII); A, g, L, N, D, H, K, B, E, C, M, I; a les de (Oll.47), (Bub.52); a,f,l,h,g,d,n,k,b,e,c,m,i. 

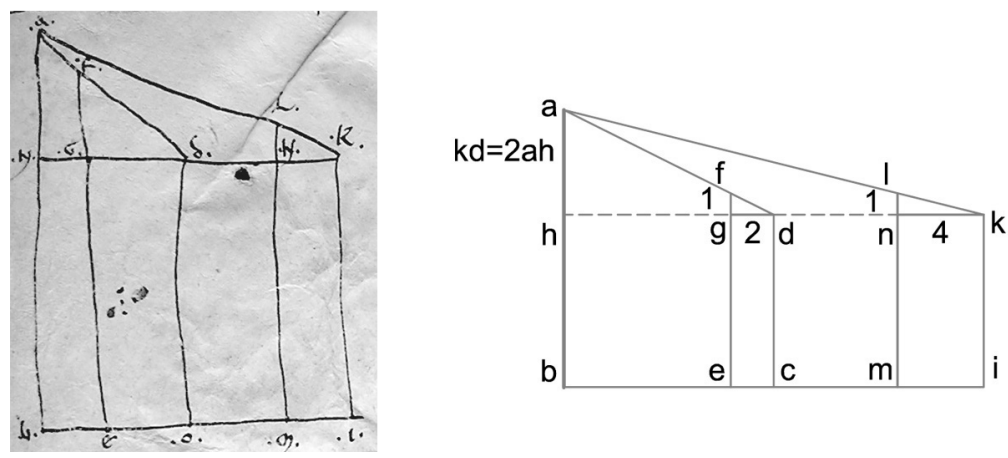

Fig. 13. Interpretació. Proposició 15 de Gerbert del còdex 80 ACTo.

A la interpretació (P-15b); [.a.; .f.; .l.; .n.; .g.; d.; .h.;.k.; .b.; .e.; .o.; .m.; .i.], a les edicions gràfiques; (Pez.XXVII), (Oll.47) i (Bub.52).

Existeix una errada tant en la interpretació gràfica com al text. Per realitzar la correcta interpretació del text Post hec $k n$, $n$ l in quadrupla proporcione conferatur, et similiter [totum] $r h$, $h$ a quadruplum indubitanter dicatur, ha de ser $k h, h$ a quadruplum indubitanter. La qual cosa també provoca un vall de lletres al gràfic en la $(n)$ i la $(k)$.

La proposició planteja l'amidament de la altura d'un cos; la interpretació gràfica de la mesura té com a base tres triangles de referència, el de la mesura real, al gràfic $(\mathrm{P}-14 \mathrm{~b}),(a, n, k)$ i dos de construccions auxiliars, $(l, h, k)$ i el $(f, g, d)$.

El procés ve a determinar l'alçada mitjançant la distància que recorre el qui realitza la pràctica, similar a les practicades en l'astrolabi a les proposicions P-3 i P-4. El procés es realitza mitjançant dues estacions de referència, en les dades de referència de l'estatura del geòmetra $(i, k)$ i la de la canya, bastó o jaló $(l, m)$, amb la referència visual ortogonal a l'alçada dels ulls $(k, n)$. En la primera estació situada en el punt $(i)$, es planta el bastó d'alçada $(l, m)$, s'estableix llavors un triangle visual entre la distància de l'observador al bastó $(l, n, k)$ i a la referència que es vol mesurar $(a, h, k)$, la proporció dels costats de la base dels triangles és quatre vegades la seva alçada; així $(n k=4 l n)$ i $(h k=4 a h)$. Es trasllada després l'observador a una segona estació $(o)$, realitzant una operació similar, de manera que la proporció del triangle $(a, h, d)$, que té de base $(h, d)$, és el doble de la seva altura $(h, a)$, llavors $(h d=2 h a)$, de la mateixa manera que $(h k=4 a h)$. D'aquesta manera la distància que recorre el geòmetra entre les dues estacions de mesura $(i)$ i $(o)$, determinada a la proposició com $(k d)$, es el doble que l'alçada que es vol mesurar $(h a)$. Afegirà que si l'alçada de l'objecte i la del geòmetra son iguals no es pot realitzar la pràctica de la mesura. 
PROPOSICIÓ 16. Ad planum cum virga vel harundine mensurandum, parell a la de les edicions; Caput XXVIII (Pez), Ad metiendam planitiem per arundinem del Caput XIX de (Oll) i a la proposició del Liber III.14 (Bub) ${ }^{54}$. Per mesurar un pla amb una vara o canya.

f. 160. Ad planum cum virga vel harundine mensurandum Stans mensor in meciende planiciei extremitate conponat sibi harundinem minorem sue longitudinis prolixitate; que scilicet tandiu diversis in locis planicięi [directa figatur, donec per summitatem ipsius arundinis altera extremitas planiciei]:
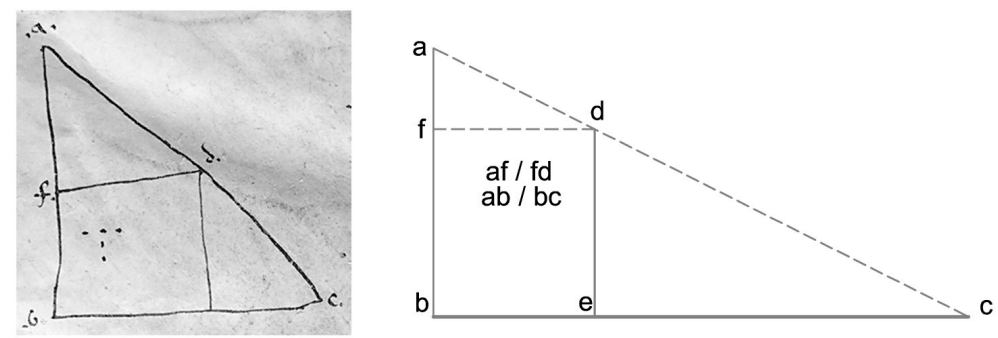

Fig. 14. Interpretació. Proposició 16 de Gerbert del còdex 80 ACTo.

Les edicions gràtiques (P-16b), [.a.; .f. .d.; .b.; .c.;]. (Pez.XXVIII), (Oll.48) i (Bub.53). A la proposició gràfica (P-16b) $a, b, c, d, f$, falta per una correcta interpretació la lletra (e) de la: canna, quum qua mensurabitur, $d e$, linea ortogonaliter ducta $d f$. Es determinen dos triangles per poder realitzar la mesura, el triangle principal $(a, b, c)$ i l'auxiliar $(a, f, d)$.

La pràctica desitja determinar l'amidament d'un punt llunyà $(c)$ i per tant la distància $(b, c)$, i es realitza coneixent l'estatura de geòmetra $(a, b)$ i mitjançant un element auxiliar, un bastó que anomena canya $(d, e)$. Es col-loca la referència per sota de l'ull del observador, entreguardant l'altura de la canya $(d, e)$, determinat ortogonalment la $(d, f)$ sobre el pit del geòmetra. Compara llavors el triangle $(a, f, d)$ amb el $(a, f, d)$, diu que la relació entre $(a, f)$, que és la distància entre els ulls i el pit, i $(f, d)$ que és la distància entre la canya i l'observador, és la mateixa que existeix entre $(a, b)$ i $(b, c)$. Conclou dient que si $(a, f)$, és la quarta part de la distància $(f, d)$, llavors l'alçada del geòmetra és la quarta part de la distància que es vol determinar ${ }^{55}$.

\footnotetext{
${ }^{54}$ Pez 1853, pp. 124-125; Olleris 1867, p. 438; Bubnov 1899, pp. 326-327; Figures (Pez. XXVIII) A,F,D,B,E,C, (Oll.48), (Bub.53), a,f,d,b,e,c.

${ }^{55}$ Aquesta proposició molt similar a la proposició $\mathrm{P}-13$ d'aquest mateix còdex, pot tenir com a referència l'Òptica d'Euclides, (Opt. P-21): Conèixer quina mida té una longitud donada, Eu- 
Proposició 17. Ad mensurandum puteum del Caput XXIX de (Pez), la del Caput XXI enunciada com a Ad puteum cum arundine mensurandum en la de (Oll), igual que la del Liber III.15 de (Bub) ${ }^{56}$. Per mesurar un pou amb una canya.

f. 160. Ut in superiori figura putei dictum est, primo a geometra perpendatur diligenter, quatenus circumduccio putei circularis habeatur; deinde cujus quantitatis sit diametrum, inquiratur. Qua inventa, stans mensor super summitatem

A la interpretació (P-16b); f,a,b,f,c,d, està repetida la lletra $(f)$ que sobre la línia $(a, f, c)$ ha de ser $(a, e, c)$. Es determinen dos triangles principals el $(\mathrm{f}, \mathrm{a}, \mathrm{e})$ i el $(\mathrm{f}, \mathrm{c}, \mathrm{a})$ que són oposats pel vèrtex $(e)$.

L'objectiu de pràctica de la mesura és similar al de la proposició P-6, on utilitzava el quadrant en aquest cas, i en una estratègia diferent ho fa amb una vara auxiliar situada al brocall del pou. Es coneix l'alçada del geòmetra $(a, f)$ i l'amplada del pou $(a, c)$, es col-loca el qui realitza la pràctica sobre el pou $i$ entreguarda la profunditat d'aquest, de manera que la visual queda reflectida sobre el escorpio situat a la boca del pou i determinat pel punt (e). Determina llavors la proposició que hi ha una relació de proporcionalitat entre l'alçada del geòmetra $(a, f)$ i la projecció de la visual $(a, e)$, de la mateixa manera que hi és entre l'alçada total de pràctica de la mesura $(b, f)$, que és la de observador $(a, f)$ més la profunditat del pou $(a, b)$ i la de l'ample del pou $(a, c)$. Planteja el cas particular que si la relació de l'alçada en la visual sobre el brocall és de 4/1 també ho serà l'amplada del pou $(a c)$ respecte a l'alçada total $(f b)$; llavors $4 f b$ / $a c$ on ( $a c$ ) és una mesura coneguda. En el gràfic (P17-b). [.f. .a.; .b; .f. c.; d.;]. En les edicions les figures; (Pez.XXIX), (Oll.42), (Bub.54) ${ }^{57}$.

clides 2002, p. 153. La diferència entre les P-12 i la P-15 de l'ACTo 80, és que la P-12 utilitza en l'aplicació pràctica la proporcionalitat dupla, mentre que la P-14 utilitza la quadrupla.

${ }^{56}$ Pez 1853, pp. 125-126; Olleris 1867, p. 432; Bubnov 1899, p.327. Figures: (Pez.XXIX) F,4,A 4,E,C,8,B,D, (Oll.42) f,IV,IV,a,c,VIII,b,d; a la de (Bub.54), f,a,e,c,b,d.

${ }^{57}$ La proposició apareix també a l'Òptica P-20 d'Euclides. Euclides 2002, pp.152-153. Proposició 20 . Conèixer quina mida té una profunditat donada. Sigui A $\Delta$ la profunditat donada i sigui E l'ull i sigui necessari conèixer la mida de la profunditat. Incideix a la vista el raig de sol $\mathrm{E} \Delta$ que coincideix amb el pla amb el punt $\mathrm{B}$ i amb la profunditat a $\Delta$. I perllongui's BZ en línia recta des de B i traci's EZ perpendicular a la recta BZ des de E. Així, donat que l'angle corresponent a EZB és igual al corresponent a BA $\Delta$, és igual al corresponent a EBZ, també el tercer, el corresponent a BEZ és igual al corresponent a $\mathrm{A} \triangle \mathrm{B}$. Per tant, el triangle $\mathrm{A} \triangle \mathrm{B}$ és equiangle respecte al triangle BEZ. Per tant, els costats seran proporcionals. Llavors EZ és a ZB com $\triangle \mathrm{A}$ $\mathrm{a} A \mathrm{AB}$. I la raó de $\mathrm{EZ}$ a $\mathrm{ZB}$ és coneguda, llavors la raó de $\triangle \mathrm{A}$ a $\mathrm{AB}$ també és coneguda; i també $\mathrm{AB}$ és conegut. Per tant, també $\mathrm{A} \Delta$ és conegut. 

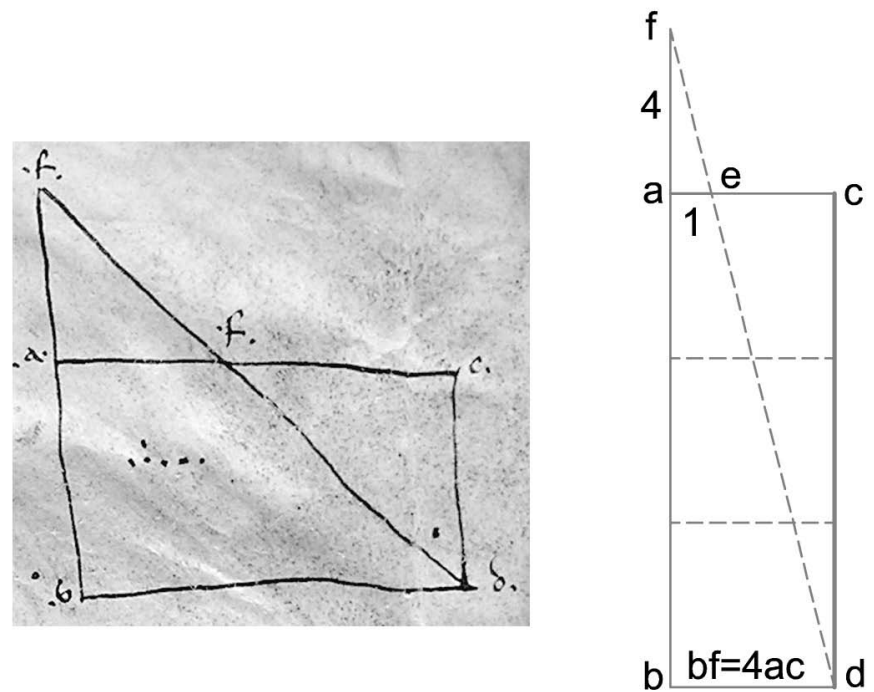

Fig. 15. Interpretació. Proposició 17 de Gerbert del còdex 80 ACTo.

Proposició 18. Ad altitudinem cum orthogonio in planitie metiendam del còdex que es l'editada al Caput XXX (Pez), el mateix Caput XXX definida com a Ad altitudinem cum orthogonio en la edició de (Oll), i la del Liber III.16 (Bub) ${ }^{58}$. Per mesurar una altura amb un escaire.

Componatur a geometra ortogonium basi katetoque ejusdem numeri conpositum, ypotenuse vero proporcio pretermittatur, quae ad altum investigandum in hoc ortogonio prorsus inutilis judicatur. Compositum nanque tandiu per planum a mensore trahatur, [donec] oculo [h]umi apposito per kateti.

Compongui el geòmetra un escaire format d'una base i d'un catet de la mateixa longitud, passi's per alt la proporció de la hipotenusa, la qual hom pensa que en aquest escaire és absolutament inútil per mesurar una altura. El mesurador porti durant un cert temps l'escaire fabricat a través de la superfície plana fins que amb l'ull posat arran del sòl vegi el punt més alt de l'altura que ha de ser coneguda per mitjà del punt més alt del catet. Un cop vist aquest punt, des del lloc on era fixada la vista, ha de mesurar-se la superfície plana

${ }^{58}$ Pez 1853, p. 126; Olleris 1867, pp. 438-439; Bubnov 1899, pp. 327-328. Figures: (Pez. $\mathrm{XXX}$ ); "hic adde staturam si vis addere pedes id est crura que similia sunt statura, altitudo, orthogonium, planities"; a les de (Oll.49), (Bub.55), totes dos "altitudo, orthogonium, planities". 
fins a la base; i quanta ella sigui, tanta serà l'altura. La qual cosa, perquè sigui entesa millor, l'escaire amb l'altura a mesurar ha de ser posat figuralment sota la visual del mesurador.

En ACTo (P-18b) [altitudo meciende] [.planicies.] [per ortogonii.; .statura mensoris.]. (Pez. XXX)(Oll.49), (Bub.56).
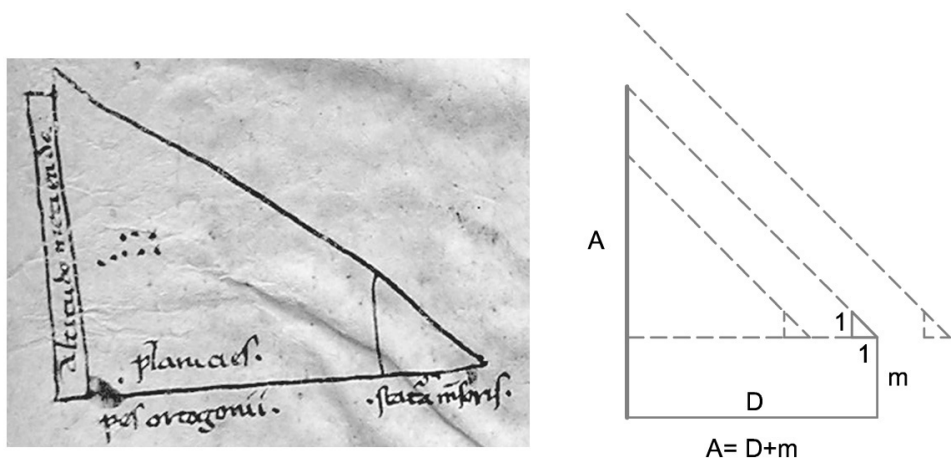

Fig. 16. Interpretació. Proposició 18 de Gerbert del còdex 80 ACTo.

PROPOSICIÓ 19. Hec adde staturam suus addere pedem, que es la proposició del Caput XXXI (Pez), la reconeguda com a Orthogonium pythagoricum ad metiendam altitudinem al Caput XXXI de (Oll) i la del Liber III.17 $(\mathrm{Bub})^{59}$. Escaire pitagòric per mesurar una altura.

f. 160v.Est eciam aliut estimande altitudinis orthogonium, [quod] ab inventore denominative nuncupatur Pitagoricum, naturalibus proporcionibus kateti, basis, ypotenuse conpaginatum: katheto III insignito, basi insignita IIII, [ypotenusa prenotata quinario]. Quod si volueris katetum IIII insignire, et basim.

Hi ha un altre escaire de calcular una altura, que ha estat anomenat pitagòric pel seu inventor, conformat amb les proporcions naturals de catet, base i hipotenusa: amb el catet marcat de III, la base marcada de IIII, [la hipotenusa prenotada de quinari (cinc)]. I si volguessis marcar el catet de IIII, i la base de III, et succeirà el mateix pel contrari, és a saber, que per tal que la base sigui proporcionada al catet en una sesquiterça, la hipotenusa ha de compararse a la base en una sesquiquarta. Del qual escaire, tot el que s'ha de fer ha de

${ }^{59}$ Pez 1853, pp. 125-126; Olleris 1867, p. 439; Bubnov 1899, p. 328. Figures: (Pez.XXXI); "visus, 5,3, orhtogonium, quarta auferatur" (Oll.50), (Bub.56); "visus, V, III, orhtogonium, IV". 
ser d'acord amb el que ha estat dit en la figura precedent, això és que durant un cert temps ha de ser desplaçat fins que pel punt més alt del catet sigui vist el punt més alt de la cosa a mesurar, només amb aquesta excepció, que en aquesta quantitat de la superfície plana mesurada ha de ser restada una quarta part, per aquesta raó, és a saber, que la base jacent excedeix el catet plantat amb la seva quarta part. Perquè això sigui comprès millor, pinti's també aquest escaire aquí al costat.

En les edicions gràfiques, (P-19b) [.visus.] [.iii.] [ortogonium,] [nos enim eam faciamus].

En les figures: (Pez.XXXI), (Ol1.50), (Bub.56).
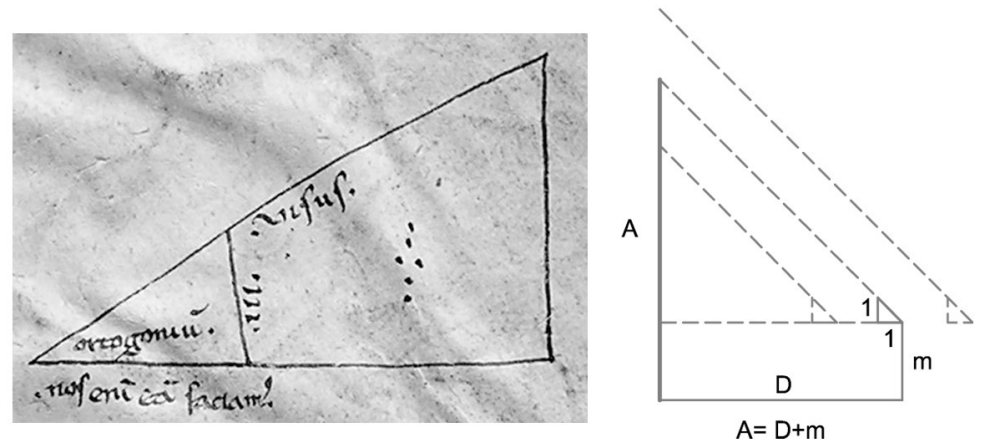

Fig. 17. Interpretació. Proposició 19 de Gerbert del còdex 80 ACTo.

PROPOSICIÓ 20. Ad altitudinem inaccessibilem cum orthogoniis contemplandam, Caput XXXII (Pez), la Ad altum ut metiatur del Caput XXXII de (Oll), i la del Liber III.18 (Bub) ${ }^{60}$. Per mesurar una altura.

f. 160v. Ad rem inaccessibilem nobis altioribus ut meciatur, quamvis laboriose, hujusmodi facimus figuram. Sit rei meciende quantitas a b, et, quot cubitorum, vel ulnarum, vel pedum, vel digitorum, vel eciam unciarum, vel cujuslibet alterius mensure sit nobis propositum scire.

${ }^{60}$ Pez 1853, p. 127; Olleris 1867, pp. 439-441; Bubnov 1899, pp. 328-330. Figures: (Pez. XXXII); U,D,H,Z,A,E, spatium inmeabile, G; a (Oll.52), u,h,z,d,a,c,b,e; a la de (Bub.57), $\mathrm{u}, \mathrm{h}, \mathrm{z}, \mathrm{d}, \mathrm{a}, \mathrm{g}, \mathrm{b}, \mathrm{e}$. 

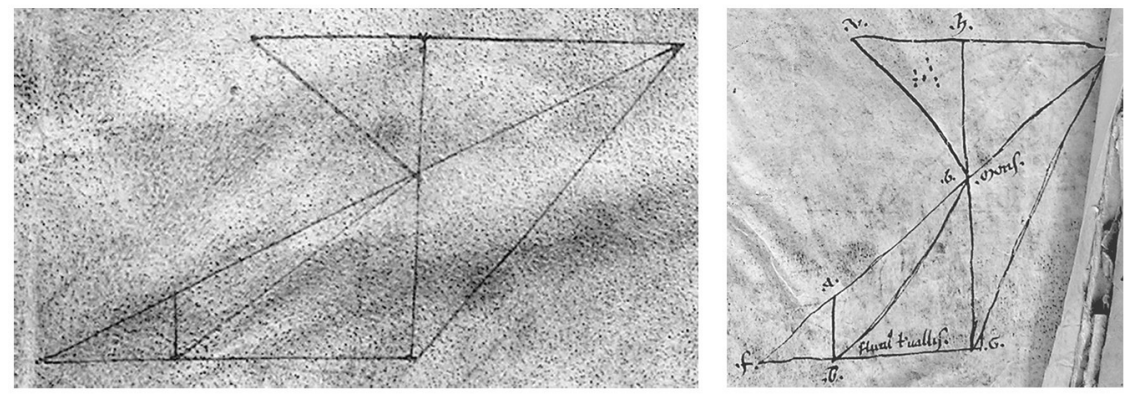

Fig. 18. Gràfics (P-20a) i (P-20b) de la Proposició 20 de Gerbert del còdex 80 ACTo.

La figura (P-20b) [.u. .h. .z.. .b. .mons. .a. .f. .b.flumi vel vallis .g.] correspon a les edicions (Pez.XXXII), (Oll.52), (Bub.57). El còdex de Tortosa segueix la mateixa del gràfic de l'edició de Pez, en una variant diferent en la construcció auxiliar, mentre que en les edicions de Olleris i Bubnov el gràfic és simètric a les de Pez i Tortosa.

La interpretació gràfica no és del tot correcta ja que el copista cau en diverses errades, en l'edició de les referències com en la pròpia construcció geomètrica lógica, igualment que la figura de l'edició de $\mathrm{Pez}^{61}$. La pràctica té com a objectiu resoldre mesures des d'algun punt alt, d'un element $(a b)$, com, per exemple, des d'una muntanya, on el peu no hi té accés, amb l'ajuda d'una construcció auxiliar. La mesura que s'empra ha de venir expressada en colzes, braces també alnes (ulnarum $)^{62}$, peus, dits, polzades.

${ }^{61}$ La representació gràfica de l'edició de Pez també porta a dificultats en la interpretació del text, i no és del tot correcta, donat que la mesura que es vol determinar és (ab) i l'element de suport és (dc). La línia EDH ha de ser una recta contínua, igualment que la [B]DU, la línia DH ha de ser paral-lela a EG.

${ }^{62}$ La mesura no apareix a la primera proposició del text; l'alna era utilitzada a la Catalunya Vella entre els segles X-XIII, en diverses mesures, Alsina 1996, pp.116-117. Tradueixo com a braça, igualment que el braccio, mesura utilitzada a una part d'Itàlia, que va del muscle a la mà. 

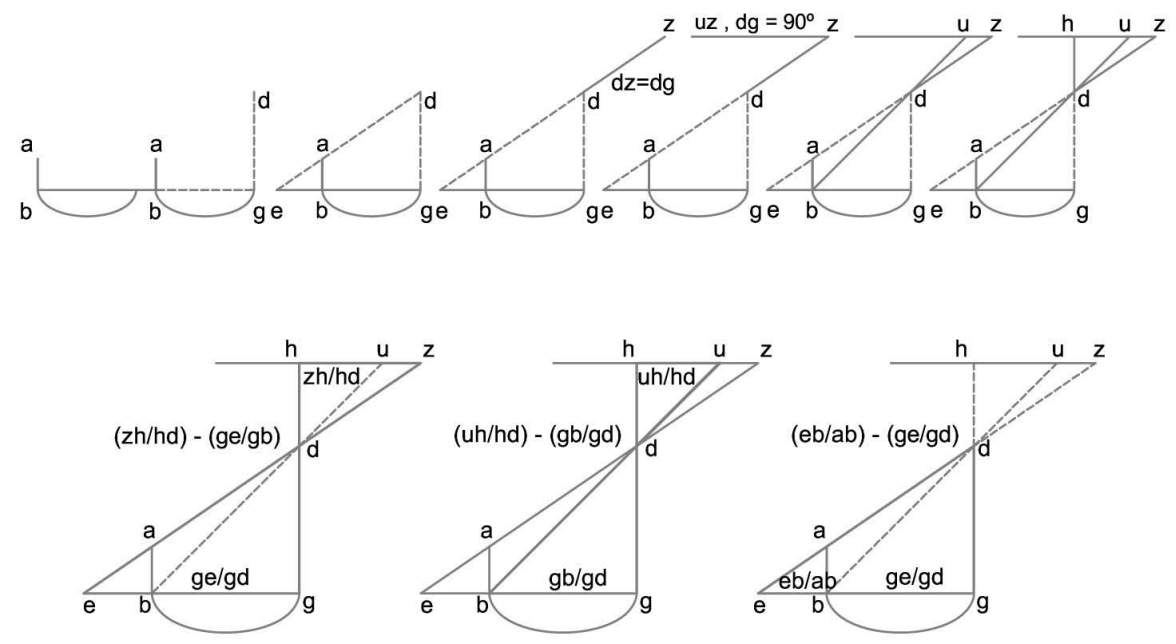

Fig. 19. Proposició 20 de Gerbert del còdex 80 ACTo.

En primer lloc existeix una distància entre l'objecte $(a b)$ on es realitzarà la construcció geomètrica, spatium immeabile inter nos et, definit com el punt $(g)$. Aquí es construeix una primera construcció auxiliar, definit com ortho(go)nium $d g$, que pot ser una simple estaca o un element de referència com pot ser un arbre $(d g)$. Després ve una altra estació, construïda en alçada, a una certa distància de l'estaca $(d g)$, de manera que es situa entreguardant el cap de l'estaca $(d g)$ i l'alçada a mesurar $(a b)$, es situa la intersecció de la visual amb terra el punt $(c)$. A la línia determinada per $(a d)$ es situa un punt que s'anomena $(z)$, a una distància del punt $(d)$, igual que l'estaca i sobre aquest punt es situa una perpendiculat a l'estaca $(d g)$, que pot ser un regle. Sobre aquesta construcció es situa concretament el punt $(u)$, de manera que aquest és coincident en la visual del cap de l'element de referència $(d g)$ que és $(d)$, i del peu de l'element a mesurar $(a b)$ que és $(b)$. Una segona visual sobre la línia $(z u)$ determinarà el punt $(h)$, coincident amb el plom del cap de l'element de referència $(d g)$.

Determina que existeix una proporcionalitat entre els triangles de la construcció auxiliar $(z, h, d)$ i el de la referència $(d g e)$, per proporcionalitat; com són coneguts $(z h)$ i $(h d)$ i l'estaca $(g d)$ es pot determinar la distància $(g e)$. Llavors opera amb els triangles $(\mathrm{u}, h, d)$ i el de la referència $(d g b)$, per proporcionalitat; com són coneguts $(u h)$ i $(h d)$ i l'estaca $(g d)$ es pot determinar la distància que separa l'estaca i l'element a mesurar $(g b)$. Finalment una proporcionalitat entre els triangles $(d g e)$ i $(e b a)$, on són conegudes les mesures 
de l'estaca $(g d)$ la distància que separa l'estaca i l'element a mesurar $(g b)$ al $(d g e)$, i a l'altre es conegut el catet $(e b)$, per diferència entre $(e g)$ i $(b g)$, llavors es pot determinar l'alçada a determinar $(a b)$.

\section{DE eRGaStiCIS SCHEMATIBUS DE LA GEOMETRIA DE MARCIÀ CAPELla}

Després de Gerbert, tenim un fragment de l'obra De Nuptiis Philologiae et Mercurii de Marcià Capella, del Llibre VII de la Geometria (f. 160v.28- f. 161r.5), dintre de l'edició teubneriana de Willis de Leipzig ${ }^{63}$, la que pertany a l'Ergasticis Schematibus [715]. Es coneixen dos-cents quarantaun manuscrits del text als quals haurà d'afegir-se la excerpta del ACTo $80^{64}$. El text de Capella és d'època merovíngia en la recensió de 534 de Securo Félix (534); la majoria de còdexs són del període carolingi, després es conserven diversos comentaris de Joan Scott Eriúgena i de Remigi d'Auxerre. Els més tardans del segle XII apareixen en forma d'excerpta del còdex ACTo 80, fins arribar a l'editio princeps de Vicenza (1499) de Franciscus Vitalis Bodianus ${ }^{65}$. El text comenta:

f. 160v. [In his generibus] planorum alia scemata dicuntur Ergastica, alia Apodictica. Ergastica [sunt], que faciende cuiuslibet forme precepta continent. Apodictica, que probandi, quod asseverant, afferunt documenta. Verum Graecis nominibus sic appellantur: Primus Sistaticus. Secundus, Idmematicus. Tercius, Anagraphos. Quartus, Engraphos. Quintus, Perigraphos. Sextus Parembolicus. VII Proseureticus. S[is]taticus.

En aquests gèneres de les figures (esquemes) planes unes són anomenats Ergàstics, d'altres Apodíctics. Els Ergàstics són aquells que contenen els preceptes per fer qualsevol figura. Els Apodíctics són aquells que aporten els documents per provar allò que afirmen. S'anomenen així amb els noms grecs: El primer, Sistàtic. El segon, Idmemàtic. El tercer, Anàgraf. El quart, Èngraf. El cinquè, Perígraf. El sisè, Parembòlic. VII Proseurètic.

f. 160v. Apodictici autem tropi ideo transeuntur, cum mihi cum Diale [c]tica, quam audistis, conmunes sint, sed omnia scemata quinque partibus.

\footnotetext{
${ }^{63}$ Willis 1983; Ramelli 2001; Ferre 2007,

${ }^{64}$ Leonardi 1959, núm. XXXIII 1959, pp. 443-489. Leonardi 1960, núm. XXXIV, pp. 1-99 i pp. 411-524.

${ }^{65}$ Traducció espanyola d'aquest fragment a Ayuso 2008, pp. 274-279; Ayuso 2011, pp. $149-170$.
} 
Ara bé, els trops (mètodes) Apodíctics són omesos perquè per a mi són comuns amb la Dialèctica, que heu escoltat, però tots els esquemes vénen expressats en cinc parts, que són comunes amb la Dialèctica, les quals han estat anomenades pels Grecs d'aquesta manera: la primera Pròtasis, la segona Diòrismos, la tercera Kataskeue, la quarta Apodeixis, la cinquena Sumperasma. En llatí podem interpretar-ho així: la primera és la proposició de l'esquema, la segona és la determinació de la qüestió, la tercera és la disposició dels arguments, la quarta és la demostració i comprovació de la sentència, i la darrera és la conclusió. Sigui dit això dels gèneres dels plans; ara tornem als membres dels teoremes; puix aquests són certament la línia i l'angle.

f. 160v. Hujus autem collacionis iiiior sunt species: Prima dicitur Ysotes. Secunda Omologos. Tercia Analogos. Quarta Alogos. Ysotes est cum collata consenciunt Omologos, cum due linee pares uni medię duplo parilive conferuntur.

Ara bé, d'aquesta comparació o relació n'hi ha quatre espècies: la primera s'anomena Ysotes. La segona Omologos. La tercera Analogos. La quarta Alogos. La Ysotes és quan els elements comparats o relacionats s'harmonitzen. Omologos, quan dues línies iguals a una tercera mitjana es relacionen en el doble o en igual. Analogos, quan una línia dominada per una altra excedeix a aquesta en el doble. Alogos, però, és la que en cap de les seves parts s'harmonitza amb una altra ni en igualtat, ni en la mitja o tercera part ni en el doble o el triple.

f. 160v. Omnis autem linea aut rete dicitur aut Alogos. Rete autem [illa est], que prior proponitur, aut que proposite lineę communi mensura confertur. Reton autem dicitur quicquid [convenit]. Proposita autem linea, quamvis collata.

Puix tota línia és anomenada rete (racional) o Alogos (irracional). La línia racional és aquella que es proposa en primer lloc, o la que s'harmonitza amb una mesura comuna a qualsevol línia proposada. Racional hom diu tot allò que harmonitza. Així, doncs, una línia proposada, encara que no hagi estat relacionada o comparada, tanmateix perquè encara no és Alogos (irracional) comparada amb una altra, i té certament la condició que per ella sola assoleix perfectament la racionabilitat, s'anomena rete (racional). Tanmateix, un cop relacionada o comparada, la línia es torna Alogos (irracional) si es troba que és dissonant o disharmònica per tot arreu.

f. 160v. Lineas [autem] que sibi conseciunt, simmetras [dicimus; quae non] consentiunt, [asimmetras. Et non mensura sola, sed et potentia symmetras facit, et dicuntur Dunamei Simmetroi]; in 
mensura autem pares Mese simmetre appellantur. Ergo cum tam mensura quam potentia con[ferant]ur, omnes, que...

Les línies, però, que són adequadament proporcionades, les unes parts amb les altres, i també amb el tot, les anomenem simètriques; les que no són adequadament proporcionades, les anomenem asimètriques. I no és solament la mesura, sinó també la potència la que les fa simètriques, i per això s'anomenen en grec Dynamei Simmetroi; si són iguals en la mesura s'anomenen simètriques per la mesura. Per tant, quan es posin en relació tant la mesura com la potència, totes aquelles línies que discrepen, sigui en la potencia sigui en la mesura, són asimètriques.

f. 160v. Ex his aloge XIII fiunt, quarum prima dicitur Mese Alogos; secunda Ek Duoin Onomaton Alogos. Huius species sunt VI: Quarum prima dicitur Prote Alogos. Secunda similiter Deutera. Item, trite et cetere deinceps. Item, tercium genus dicitur Ek Douo Meson.

D'aquestes, n'hi ha tretze aloge (irracionals), la primera de les quals s'anomena Mese Alogos (Irracional per la mijana). La segona, Ek Duoin Onomaton Alogos (Irracional per la doble denominació). Les d'aquesta espècie són sis: la primera de les quals s'anomena Prote Alogos (Primera Irracional). La segona, semblantment, Deutera (Alogos) (Segona Irracional). I, tot continuant, la Trite (Tercera) i les altres que segueixen. Més, el tercer gènere s'anomena Ek Duo Meson Prote Alogos (Primera Irracional per les dues mitjanes) i de manera semblant, com més amunt s'ha dit. El Quart és el Ek Douoin Meson Deutera Alogos (Segona Irracional per les dues mitja$n e s$ ). El cinquè gènere s'anomena Mixton Alogos (Irracional mixt). El sisè s'anomena Reton kai Meson Dinamene Alogos (Irracional per la potència de racionals i mitjanes). El setè és el Duo Mesa Dunamene Alogos (Irracional per la potència de dues mitjanes). El vuitè és l'Apotome Alogos (Irracional tallat o seccionat). D'aquest n'hi ha sis espècies: la primera, la segona, la tercera i d'aqui successivament s'anomenen com més amunt. El novè gènere és el Mesos Apotome Prote Alogos (Primer Irracional de la mitjana seccionada). El desè és l'Apotome Deutera Alogos (Segon irracional seccionat). L'onzè és l'Elasson Alogos (Irracional dels elements menors). El dotzè és l'Alogos Meta Proton Meson to Olon Poiousa (Irracional que engendra el tot després de la primera mitjana). El tretzè és l'Alogos Meta Meson Meson to Olon Poiousa (Irracional que engendra el tot després de la mitjana mitjana). Totes aquestes irracionals combinades amb d'altres línies, mentre porten les seves pròpies forces o reben les forces alienes, demostren amb diverses raons o arguments uns certs tipus d'espais, que els Grecs anomenen chōría (camps). 


\section{LA GLOSSA D’AL-HAJJĀJ ALS ELEMENTA D’EUCLIDES}

Hec est de abecedario.

Ait Elhageth dic [it] quia linea longior cum proporcionaliter in potencia. [Biteg dixit] ad quadratum suum erit remocius racionali in porcione illo quod est eo remocius. Quem prima Surdare erit latus, post ea erit secunda latus Latans, deinde erit tercia latus lateris, deinceps quia eodem modo extra extremitates semper remociores, quadrato racionali [est] in portione illo quod est eo remocius. Intellige ergo, [nullus] angulus rectilineus potest [circa] tam parvus qui non [posit] esse [illo], quod angulus $a b d$ non potest minor ut apparet in hac figura, quia angulus $c$ et angulus $d$ uterque eo minor, id est $a[b] d$ ex XVI primi eodem [modo] nec $d$, quia $c$ et $e$ uterque minor. Et sic si aliquis ponatur essę [miramus] non [erit] omnes ites anguli equo trigoni ubi duo recti aut erit aliquis minor minimo.

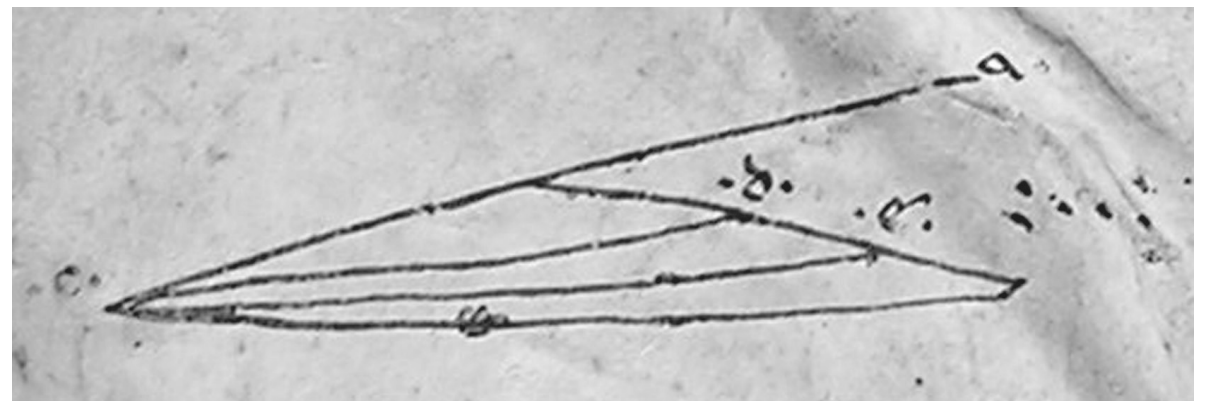

Fig. 20. Glossa als Elementa de Euclides de Al-Hajjāj

Passatge o glossa als Elementa de Euclides d'Al-Hajjāj ibn Yūsuf ibn Mațar (786-833), responsable de dues versions àrabs d'Euclides ${ }^{66}$. Una possible interpretació estaria en sequiència dels nombres irracionals; amb la unitat, rel de dos, rel de tres, rel de quatre (dos unitats). Així si es construeix un quadrat de costat $(a c)$ que és la unitat, la diagonal serà $(c b)$ que és la rel de dos que és el primer dels irracionals. Després un nou rectangle de base $(a c)$ la unitat, la $(c b)$ rel de dos, la seva diagonal $(c d)$ que és la rel de tres, i així mateix un altre rectangle de base $(a c)$ la unitat y la $(c d)$ rel de tres, la seva diagonal será (ce) que són dues unitats. La construcció de successius triangles en base a la unitat i costats la sequiència dels irracionals dóna una construcció on els vèrtexs estan alineats.

\footnotetext{
${ }^{66}$ Besthorn, Heiberg 1897.
} 

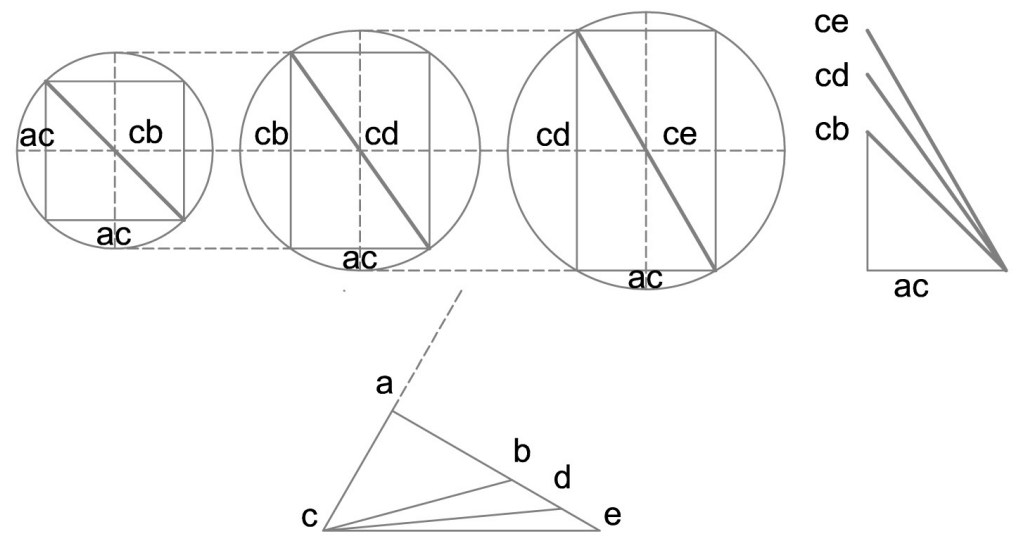

Fig. 21. Interpretació geomètrica de la seqüència dels irracionals.

Com diu el còdex: Així, el primer dels nombres irracionals serà el primer costat, després el segon costat, després el tercer i així successivament, perquè és de la mateixa manera que més enllà de les extremitats sempre més allunyades, és més llunyà en la seva porció racional allò que és més llunyà en l'anterior quadrat racional. Entén, doncs, que cap angle rectilini no pot ser tan petit que no es compleixi en ell això, és a dir, que l'angle $a b d$ no pot ser menor, com apareix en aquesta figura, perquè l'angle $c$ i l'angle $d$, ambdós són menors que ell, això és, $a[b] d$ en virtut del [teorema] XVI [del llibre primer dels Elements d'Euclides], però no $d$, perquè $c$ i $e$, ambdós, són menors. I així, si algú posés que això és d'aquesta manera, ens admiraria que tots aquests tres angles fossin iguals en el trígon, quan dos d'ells han de ser rectes, o és que aleshores algun d'ells ha de ser menor que el mínim, [cosa impossible].

\section{CONCLUSIONS}

El text de la geometria, ff. 159r-161v, és un text miscel-lani de geometria, compost per tres textos independents:

La Geometria Incerti Auctoris de l'apòcrif Gerbert d'Orlhac (ff. 159r-160v.27), del llibre III i IV, consta de 20 proporcions. El capítols de la del còdex 80 de la de la part apòcrifa de Gerbert d'Orlhac està dintre del rang de la classe $\mathrm{E}$ de la tradició manuscrita. Les fonts de les mesures indirectes tenen fonaments diferents; les definicions $\mathrm{P}-1 \mathrm{i} \mathrm{P}-2$ son gromàtiques, mentre les P3, P-4, P-5, P-6, P-7, tenen tractats de les utilitats de l'astrolabi d'origen àrab, 
el mateix que les P-8 i P-9 amb fonament de l'òptica. Altres tindran com a referents les proporcions P-18, 19, 20 i 21 de l'Òptica d'Euclides, tal com les P-10, P-11, P-13, P-15 i P-16. Finalment la proporcionalitat de triangles P-12, P-14, P-17, i P20, i aquells que tenen la particularitat de tenir un escaire isòsceles P-18, i la pitagòrica P-19. Les proposicions tenen una metrologia de proporcionalitat de base 12 , on s'utilizen, la igualtat $1 / 1$, la $1 / 2$ dupla o diapason, $2 / 3$ sesquilàtera o diapente i la $2 / 3$ sesquitèrcia o diatessaron, de base neoplatònica.

\begin{tabular}{|c|c|c|c|c|c|c|}
\hline \multicolumn{7}{|c|}{ Taula de correspondència proposicions còdex ACTo 80} \\
\hline Proposició & Utilitat & Tractat & Estacions & Metrica & Porporcionalitat & Antecedents \\
\hline P-1 & Definició & Geometria & & & & Gromàtics \\
\hline P-2 & Definició & Mesures & & & & Gromàtics \\
\hline P-3 & Astrolabi & $\begin{array}{l}\text { Alçada } \\
\text { Astrolabi }\end{array}$ & 1 & $1 / 1$ & Igualtat & Utilitats astrolabi \\
\hline P-4 & Astrolabi & $\begin{array}{l}\text { Alçada } \\
\text { Astrolabi }\end{array}$ & 2 & $3 / 4$ & Sesquitèrcia & Utilitats astrolabi \\
\hline P-5 & Astrolabi & $\begin{array}{l}\text { Planura } \\
\text { Astrolabi }\end{array}$ & 2 & $2 / 3$ & Sesquilatera & Utilitats astrolabi \\
\hline P-6 & Astrolabi & $\begin{array}{l}\text { Alçada } \\
\text { Astrolabi }\end{array}$ & 1 & $3 / 12$ & Quadrupla & Utilitats astrolabi \\
\hline P-7 & Astrolabi & $\begin{array}{l}\text { Profunditat } \\
\text { Astrolabi }\end{array}$ & 1 & $4 / 12$ & Tripla & Utilitats astrolabi \\
\hline P-8 & Astrolabi & $\begin{array}{l}\text { Alçada } \\
\text { Astrolabi } \\
\text { Ombra }\end{array}$ & 1 & & & $\begin{array}{l}\text { Utilitats astrolabi, } \\
\text { Optica }\end{array}$ \\
\hline P-9 & Astrolabi & $\begin{array}{l}\text { Alçada } \\
\text { Astrolabi } \\
\text { Ombra }\end{array}$ & 1 & & & $\begin{array}{l}\text { Utilitats astrolabi, } \\
\text { Optica }\end{array}$ \\
\hline P-10 & Mirall & $\begin{array}{l}\text { Alçada } \\
\text { reflexió }\end{array}$ & 1 & $1 / 2$ & Dupla & Òptica \\
\hline P-11 & Ombra & $\begin{array}{l}\text { Alçada } \\
\text { Ombra }\end{array}$ & 1 & & & Òptica \\
\hline P-12 & Bastons & $\begin{array}{l}\text { Alçada } \\
\text { bastó }\end{array}$ & 1 & $1 / 1$ & Igualtat & Proporcionalitat \\
\hline P-13 & Bastons & $\begin{array}{l}\text { Planura } \\
\text { bastó }\end{array}$ & 1 & & & Òptica \\
\hline P-14 & Bastons & $\begin{array}{l}\text { Alçada } \\
\text { bastó }\end{array}$ & 1 & $1 / 2$ & Dupla & Proporcionalitat \\
\hline P-15 & Bastons & $\begin{array}{l}\text { Alçada } \\
\text { bastó }\end{array}$ & 2 & $1 / 2,1 / 4$ & $\begin{array}{c}\text { Dupla, } \\
\text { quàdrupla }\end{array}$ & Proporcionalitat \\
\hline
\end{tabular}




\begin{tabular}{|c|c|l|c|c|c|c|}
\hline P-16 & Bastons & $\begin{array}{l}\text { Planura } \\
\text { bastó }\end{array}$ & 1 & & & Òptica \\
\hline P-17 & Bastons & $\begin{array}{l}\text { Profunditat } \\
\text { bastó }\end{array}$ & 1 & $1 / 4$ & Quàdrupla & Òptica \\
\hline P-18 & Escaire & $\begin{array}{l}\text { Alçada } \\
\text { escaire }\end{array}$ & 1 & $1 / 1$ & Igualtat & Proporcionalitat \\
\hline P-19 & Escaire & $\begin{array}{l}\text { Alçada } \\
\text { escaire }\end{array}$ & 1 & $3 / 4$ & Sesquitèrcia & Proporcionalitat \\
\hline P-20 & Bastons & $\begin{array}{l}\text { Alçada } \\
\text { bastó }\end{array}$ & 2 & & & Proporcionalitat \\
\hline
\end{tabular}

La singularitat del còdex és la interpretació de la proposició núm. 20. A les edicions d'Olleris i de Bubnov la construcció auxiliar, sobre la muntanya, es construeix amb un element auxiliar vertical, que pot ser un regle o plomada $(u, h, z)$, a diferència de la de Pez i la de l'ACTo, que es realitza sobre un regle horitzontal $(u, h, z)$. La conclusió d'Olleris i Bubnov és que la proporció dels visuals al cap i peu de l'element a mesurar $(a b)$ sobre la construcció auxiliar $(u, h, z),(u / z, . u / h)$ guarda la mateixa proporcionalitat que la primera estaca $(d g)$ amb l'element a mesurar $(a b)$.

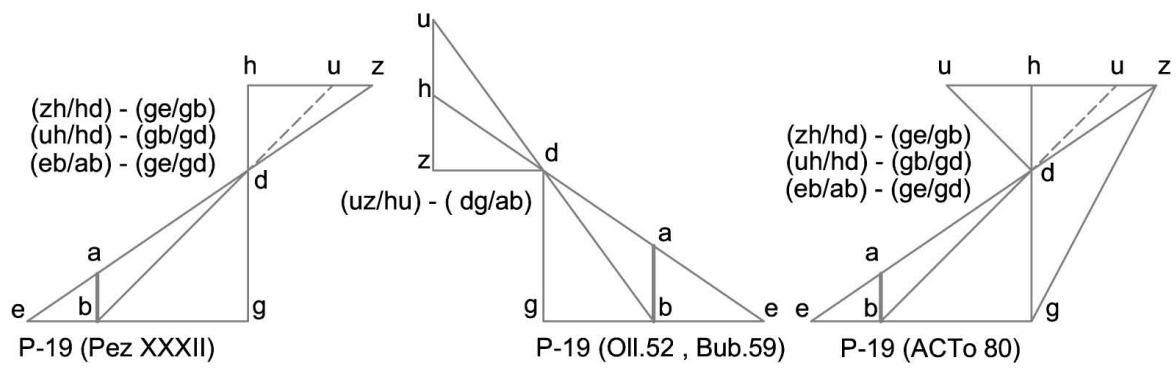

Fig. 22. Comparació dels gràfics de les interpretacions de la Proposició 20 de Gerbert del còdex 80 ACTo.

El gràfic del còdex de Tortosa utilitza un escaire en la visual $(b d)$ sobre el punt $(d)$ per determinar el punt $(u)$ i així $(u h)$, a diferència del de l'edició de Pez, que perllonga la visual (bd) fins a trobar l'horitzontal $(h z)$.

El manuscrit es completa amb un fragment de l'obra De Nuptiis Philologiae et Mercurii de Marcià Capella, que pertany al De Ergasticis Schematibus del Llibre VII de la Geometria (ff. 160v.28-f. 161r.5), i amb la glossa als Elementa d'Euclides d'Al-Hajjāj ibn Yūsuf ibn Mațar (f. 161r.6- f. 161r.13). 
L'Arxiu Capitular de Tortosa conté nombroses referències a la matemàtica medieval, en especial a la proporcionalitat medieval i a la seva base metrològica. Si a la citada obra de Calcidi (f. 146r), amb clares referències a la teoria de la proporcionalitat medieval, i al fragment de la de Capella li afegim el Commentarius in somnium Scipionis de Macrobi (ff. 1r-62v) i el còdex 236 d'aquest mateix autor, estaríem davant dels principals comentaristes de l'obra neoplatònica. Les obres matemàtiques es completen amb una numeració de posició elaborada en l'entorn d'Hug de Sant Víctor (f. 162r).

Tractant-se d'un text manuscrit de la segona meitat del segle XII, ens plantegem la hipòtesi de la connexió amb el cenobi i escriptori de Ripoll a través de l'abat del monestir Ripoll i de Sant Joan de les Abadesses, Ponç de Monells (c.1120-1193), qui va ser bisbe de Tortosa (1165-1193). En aquelles dades la catedral de Tortosa no disposava encara d'un Scriptorium propi i els còdexs més antics no procedien del mercat de còdexs del món cultural europeu, on, en virtut de les Constitucions Capitulars dels segles XIV i XV, els nous canonges havien d'adquirir-los per augmentar la biblioteca de l'escola catedralícia.

\section{BIBLIOGRAFIA CITADA}

Alsina, Claudi; Marquet, Lluís; Feliu, Gaspar (1996), Diccionari de Mesures Catalanes, Barcelona, Curial.

Ayuso García, Manuel (2008), La terminología latina de la geometría en Marciano Capela, Universidad Nacional de Educación a Distància, Facultad de Filología, Departamento de Filología Clásica (tesi doctoral). Vegeu: http://dialnet.unirioja.es/servlet/tesis?codigo $=38801$ [consulta: 01/06/2015].

Ayuso García, Manuel (2011), Hallazgos textuales en las ediciones postincunables de Basilea 1532 y de Lion 1539 en la sección de geometría de Marciano Capela, "Myrtia" 26, pp.149-170.

Bayerri Bertomeu, Enrique. (1962), Los Códices Medievales de la Catedral de Tortosa. Novísimo inventario descriptivo, Tortosa, Talleres Gráficos Algueró y Baiges.

Beaujouan, Guy (1985), Les apocryphes mathématiques de Gerbert, en Tosi, Michele (ed.), Gerberto, scienza, storia e mito. Atti del Gerberti Symposium (Bobbio 25-27 iuglio 1983), Bobbio, Archivi storici bobiensi, pp. 645-658.

Beda Venerabilis (1850). De rerum Nature Liber [0627-0735], en Patrologia Latina, vol. 90. MPL090.

Besthorn, Ramus Olsen; Heiberg, J.L. (1897), Codex leidensis, 399, 1: Euclidis Elementa ex interpretatione Al-Hadschdschadschii cum commen- 
tariis Al-Narizii Arabice et Latine ediderunt notisque instruxerunt R.O. Besthorn et J.L. Heiberg, Hauniae, in Libraria Gyldendaliana.

Boncompagni, Baldassarre (1862), Scritti di Leonardo Pisano matematico del secolo decimoterzo. Volume II. Leonardi Pisani Practica Geometriae es Opusculi, Roma, Tipografia delle scienze matematiche e fisiche.

Borelli, Arianna (2008), Aspects of the astrolabe: architectonica ratio in tenthand eleventh-century Europe, Stuttgart, F. Steiner.

Bubnov, Nicolaus (1899), Gerberti postea Silvestri II papae opera mathematica (972-1003), Berlín, Friedlände.

Denifle, Henry; Chatelain, Émile Louis Marie (1896), Inventarium Codicum Manuscriptorum Capituli Dertusensis, París, apud Aemilium Bouillon Editorem.

Euclides (2002), Óptica; Catóptrica; Fenómenos. Euclides, Madrid, Gredos. Ferre, Barbara (2007), Les noces de Philologie et de Mercure. Livre VI: La géometrie, París, Les Belles Lettres.

Hahn, Nan L (1982), Medieval Mensuration: Quadrans Vetus and Geometrie Due Sunt Partes Principales, Filadelfia, The American Philosophical Society.

Jacquemard, Catherine (2000), Recherches sur la composition et la transmission de la Geometria incerti auctoris, en Callebat, Louis; Desbordes, Olivier (eds), Science antique, science médiévale. Actes du colloque international (Mont-Saint-Michel, 4-7 septembre 1998), Hildesheim, Olms-Weidmann, pp. 81-119.

Jacquemard, Catherine; Desbordes, Olivier; Hairie, Alain (2007), Du quadrant vetustior à l'horologium viatorum d'Hermann de Reichenau: Étude du manuscrit Vaticano, BAV Ottob. lat. 1631, f. 16-17v., "Kentron" 23, pp 79-124.

Leonardi, Claudio (1959 i 1960), I codici di Marziano Capella, "Aevum” 33, pp. 443-489; "Aevum” 34, pp. 1-99 i pp. 411-524.

Lluís i Ginovart, Josep (2002), Geometría y diseño medieval en la catedral de Tortosa. La catedral no construida, Universitat Internacional de Catalunya (tesis doctoral).

Lluís i Ginovart, Josep (2005), Códice 80. Geometria incerti auctoris. Numeración posición. Dragmation Philosophiae, en La Llum de les Imatges. Sant Mateu 2005, València, Generalitat Valenciana, Conselleria de Cultura, Educació i Esport.

Martínez Gázquez, José; Gómez Pallarés, Joan (1994), Manuscritos científicos latinos de la catedral de Tortosa, "Hispania Sacra" 46, pp. 413-424.

Millàs Vallicrosa, Josep Maria (1931), Assaig d'història de les idees físiques i matemàtiques a la Catalunya medieval. Vol I, Barcelona, Institució Patxot. 
Moreschini, Claudio (2003), Calcidio. Comentario al Timeo di Platone, Milà, Bompiani - Il pensiero occidentale.

Mulliachus, Friedrich. G.A. (1867), Fragmenta Philosophorum Graecorum. Volumen II. Pythagoreos, Sophistas, Cynicos et Chalcidii in priorem Timaei Platonici partem comentarios continens, París, Editore Ambrosio Firmin Didot.

O'Callagahn, Ramón (1897), Los códices de la catedral de Tortosa, Tortosa, Imprenta Católica de J. L. Foguet.

Olleris, A. (1867), CEuvres de Gerbert, Pape sous le nom de Sylvetre II collationnées sur les manuscrits, précédées de sa biographie, suivies de notes critiques \& historiques, Clermond, Thibaud, - París, Ch. Dumoulin.

Petti, Raffaella (2002), Misurazioni a distanza nel rifacimento di Cristofano di Gherardo di Dino della Pratica geometriae di Leonardo Pisano, Florència, Dipartimento di Matematica "Ulisse Dini".

Pez, Bernardus (1853), SS Silvester II. Geometria [0999-1003], en Patrologia Latina, vol. 139. MPL 139.

Puigvert, Gemma (2000), Astronomia i astrologia al Monestir de Ripoll: Edició i estudi dels manuscrits científics astronomicoastrològics del monestir de Santa Maria de Ripoll, Barcelona, Universitat Autònoma de Barcelona.

Querol Lor, Aurelio (1989), 174. Còdex Miscel-lani i Factici, en Millenum. Història i Art de l'Església Catalana, Barcelona, Mackro.

Ramelli, Ilaria (2001), Marziano Capella. Le Nozze di Filologia e Mercurio. Testo latino a fronte. Introduzione, traduzione, comentario e appendici di Ilaria Ramelli, Milà, Bompiani - Il pensiero occidentale.

Ronca, Italo (1997), Dragmaticon Philosophiae, en Corpus Chistianorum. Continuatio Mediaeualis CLII. Gvillelmi de Conchis Opera Omnia. Tomus I, Turnhout, Brepols.

Rubió i Lluch, Antoni; Rubió i Balaguer, Jordi (1913-1914), La Biblioteca del Capítol Catedral de Tortosa, "Anuari de l'Institut d'Estudis Catalans" 5/2, pp. 745-757.

Sarrade, Marie-Thérèse (1986), Sur les connaissances mathématiques des batisseurs de cathédrales, París, Librairie du Compagnonnage.

Tannery, Paul (1897), Une correspondance d'écolâtres du XIe siècle, "Comptes rendus des séances de l'Académie des Inscriptions et BellesLettres" 41/2, pp. 214-221.

Tannery, Paul; Clerval, Abbé (1901), Une correspondance d'écolâtres du XIe siècle, "Notices et extraits des manuscrits de la Bibliothèque Nationale et autres bibliothèques" 36/2, pp. 487-543. 
LA GEOMETRIA DEL CÒDEX 80 (S. XII) DE LA CATEDRAL DE TORTOSA 851

Victor, Stephan (1979), Practical geometry in the high middle ages: artis cuiuslibet consummatio and the pratike de geometrie, Filadelfia, The American Philosophical Society.

Willis, James (1983), Martianus Capella, edidit J. Willis, Leipzig, Teubner.

Fecha de recepción del artículo: febrero 2013

Fecha de aceptación y versión final: marzo 2014 